Supporting Information for:

\title{
Concise Asymmetric Synthesis of (+)-CP-99,994 and (+)-L-733,060 via Efficient Construction of Homochiral syn-1,2-Diamines and syn-1,2-Amino Alcohols.
}

\author{
Run-Hua Liu, Kai Fang, Bing Wang, Ming-Hua Xu, and Guo-Qiang Lin
}
Department of Chemistry, Fudan University, 220 Handan Road, Shanghai 200433, Institutes of Biomedical Sciences, Fudan University, 138 Yixueyuan Road, Shanghai 200032, and Shanghai Institute of Organic Chemistry, Chinese Academy of Sciences, 354 Fenglin Road, Shanghai 200032, China.

wangbing@fudan.edu.cn

Table of Contents

1. General Information.

2. Experimental details for compounds 10, 11, 14, 19, 20, 21.

3. ${ }^{1} \mathrm{H}$ and ${ }^{13} \mathrm{C}$ NMR spectra for compounds $5, \mathbf{9}, \mathbf{1 0}, \mathbf{1 1}, \mathbf{1 2}, \mathbf{1}, \mathbf{1 4}, \mathbf{1 5}, \mathbf{1 6}, \mathbf{1 9}, \mathbf{2 0}, \mathbf{2 1}, \mathbf{2} . \quad$...S5-S30 
General Information. All ${ }^{1} \mathrm{H}$ NMR and ${ }^{13} \mathrm{C}$ NMR spectra were recorded at ambient temperature in $\mathrm{CDCl}_{3}$ (93.94 kG, ${ }^{1} \mathrm{H} 400 \mathrm{MHz}$ ). Chemical shifts are reported in parts per million as follows: chemical shift, multiplicity $(\mathrm{s}=$ singlet, $\mathrm{d}=$ doublet, $\mathrm{t}=$ triplet, $\mathrm{q}=$ quartet, $\mathrm{m}=$ multiplet, $\mathrm{br}=$ broad), integration, and coupling constant. Optical rotations were recorded at $589 \mathrm{~nm}$, and were reported as $[\alpha]_{\mathrm{D}}$ (concentration in grams $/ 100 \mathrm{~mL}$ solvent). Melting points were uncorrected.

\section{Compound 10:}

To a cooled $\left(0^{\circ} \mathrm{C}\right)$ solution of $9(320 \mathrm{mg}, 0.83 \mathrm{mmol})$ and $\mathrm{Et}_{3} \mathrm{~N}(0.17 \mathrm{~mL}, 1.25 \mathrm{mmol})$ in $\mathrm{CH}_{2} \mathrm{Cl}_{2}(5 \mathrm{~mL})$ was added dropwise $\mathrm{MsCl}(0.08 \mathrm{~mL}, 1.08 \mathrm{mmol})$, and the mixture was stirred at $0^{\circ} \mathrm{C}$ for $1 \mathrm{~h}$, diluted with $\mathrm{Et}_{2} \mathrm{O}(30 \mathrm{~mL}$ ), and washed successively with $1 \mathrm{M} \mathrm{HCl}$, saturated aq. $\mathrm{NaHCO}_{3}$ and brine, dried $\left(\mathrm{Na}_{2} \mathrm{SO}_{4}\right)$, filtered and concentrated under reduced pressure. The residue was dissolved in DMF (3 mL) under Ar, to this was added $\mathrm{NaN}_{3}$ (163 mg, $2.5 \mathrm{mmol}$ ) and the solution was stirred at $65^{\circ} \mathrm{C}$ overnight, cooled to rt, diluted with $\mathrm{Et}_{2} \mathrm{O}(30 \mathrm{~mL})$, and washed successively with water and brine, dried $\left(\mathrm{Na}_{2} \mathrm{SO}_{4}\right)$, filtered and concentrated under reduced pressure. The residue was purified by silica gel flash column chromatography (EtOAc/Hexanes=1/8) to afford $\mathbf{1 0}$ (280 mg, 83\%) as a white solid.

Mp. 86-87 ${ }^{\circ} \mathrm{C} ;[\alpha]_{\mathrm{D}}{ }^{23}-19.9\left(c 1.32, \mathrm{CHCl}_{3}\right) ;{ }^{1} \mathrm{H}$ NMR $\left(\mathrm{CDCl}_{3}\right) \delta$ 7.419-7.25 (m, 5H), 5.26-5.17 (m, 1H), 4.87-4.75 (m, 1H), $4.07(\mathrm{t}, 2 \mathrm{H}, J=6.0 \mathrm{~Hz}), 3.71-3.60(\mathrm{~m}, 1 \mathrm{H}), 1.92-1.72(\mathrm{~m}, 2 \mathrm{H})$, 1.70-1.59 (m, 2H), 1.43 (br s, 9H), 1.17 (s, 9H); ${ }^{13} \mathrm{C} \mathrm{NMR}\left(\mathrm{CDCl}_{3}\right) \delta 178.4,155.3,139.9,128.8$, 127.8, 126.4, 80.0, 67.3, 63.5, 57.1 (m), 38.7, 28.6, 28.3, 27.1, 25.5. ESI-MS $m / z$ 427.3 ( $\left.\mathrm{M}^{+} \mathrm{Na}^{+}\right)$; HR-ESI-MS $m / z$ Calcd for $\mathrm{C}_{21} \mathrm{H}_{32} \mathrm{~N}_{4} \mathrm{O}_{4} \mathrm{Na}$ 427.2321, Found 427.2349.

\section{Compound 11:}

To a solution of $\mathbf{1 0}$ (234 mg, $0.58 \mathrm{mmol})$ in $\mathrm{MeOH}(5 \mathrm{~mL})$ under Ar was added 30\% $\mathrm{NaOMe}$ in $\mathrm{MeOH}(0.21 \mathrm{~mL}, 1.16 \mathrm{mmol})$, the solution was stirred at $\mathrm{rt}$ for $4 \mathrm{~h}$, quenched by water, and extracted with $\mathrm{Et}_{2} \mathrm{O}(3 \times 15 \mathrm{~mL})$. The combined organic phase was washed with brine, dried $\left(\mathrm{Na}_{2} \mathrm{SO}_{4}\right)$, filtered and concentrated under reduced pressure to afford the crude product which was used in the next step without further purifications.

To a cooled $\left(0^{\circ} \mathrm{C}\right)$ solution of the crude alcohol $(180 \mathrm{mg})$ and $\mathrm{Et}_{3} \mathrm{~N}(0.11 \mathrm{~mL}, 0.84 \mathrm{mmol})$ in $\mathrm{CH}_{2} \mathrm{Cl}_{2}(5 \mathrm{~mL})$ was added dropwise $\mathrm{MsCl}(0.05 \mathrm{~mL}, 0.68 \mathrm{mmol})$, and the mixture was stirred at $0^{\circ} \mathrm{C}$ for $30 \mathrm{~min}$, diluted with $\mathrm{Et}_{2} \mathrm{O}(30 \mathrm{~mL})$, and washed successively with $1 \mathrm{M} \mathrm{HCl}$, saturated aq. $\mathrm{NaHCO}_{3}$ and brine, dried $\left(\mathrm{Na}_{2} \mathrm{SO}_{4}\right)$, filtered and concentrated under reduced pressure. The residue was dissolved in THF (5 mL) under Ar, NaH (66 mg, 60\% dispersion in mineral oil, $1.65 \mathrm{mmol}$ ) was added and the mixture was stirred at $\mathrm{rt}$ for $6 \mathrm{~h}$, quenched by saturated aq. $\mathrm{NH}_{4} \mathrm{Cl}$, extracted with $\mathrm{Et}_{2} \mathrm{O}(3 \times 15 \mathrm{~mL})$, and washed with brine, dried $\left(\mathrm{Na}_{2} \mathrm{SO}_{4}\right)$, filtered and concentrated under reduced pressure. The residue was purified by silica gel flash column chromatography (EtOAc/Hexanes=1/16) to afford $\mathbf{1 1}(139 \mathrm{mg}, 80 \%)$ as a colorless oil.

$[\alpha]_{\mathrm{D}}{ }^{23}+50.1\left(c\right.$ 1.26, $\left.\mathrm{CHCl}_{3}\right) ;{ }^{1} \mathrm{H} \mathrm{NMR}\left(\mathrm{CDCl}_{3}\right) \delta 7.45$ (d, $\left.2 \mathrm{H}, J=7.9 \mathrm{~Hz}\right), 7.37-7.22(\mathrm{~m}, 3 \mathrm{H})$, 5.47 (d, $1 \mathrm{H}, J=5.5 \mathrm{~Hz}$ ), 3.99 (dd, $1 \mathrm{H}, J=13.8,3.6 \mathrm{~Hz}$ ), 3.96-3.85 (m, 1H); 2.89 (td, $1 \mathrm{H}, J=13.2$, $3.3 \mathrm{~Hz}), 2.00-1.90$ (m, 2H), 1.88-1.76 (m, 1H), 1.75-1.60 (m, 1H), 1.42 (s, 9H); ${ }^{13} \mathrm{C} \mathrm{NMR}\left(\mathrm{CDCl}_{3}\right)$ $\delta$ 154.9, 137.7, 128.4, 128.2, 127.3, 80.2, 60.6, 56.5, 39.1, 28.3, 24.7, 23.9. ESI-MS $m / z$ 325.2 (M $+\mathrm{Na}^{+}$); HR-ESI-MS $m / z$ Calcd for $\mathrm{C}_{16} \mathrm{H}_{22} \mathrm{~N}_{4} \mathrm{O}_{2} \mathrm{Na}$ 325.1640, Found 325.1644. 


\section{Compound 14:}

To a solution of 5 (640 mg, $1.13 \mathrm{mmol}$ ) in $\mathrm{MeOH}(6 \mathrm{~mL})$ was added a methanolic solution of $\mathrm{HCl}(2 \mathrm{M}, 3.4 \mathrm{~mL})$ at $\mathrm{rt}$, stirring was continued for $4 \mathrm{~h}$, and the solution was concentrated under reduced pressure. To a cooled $\left(0^{\circ} \mathrm{C}\right)$ solution of the residue, 4-methoxybenzoic anhydride (525 mg, $1.84 \mathrm{mmol})$ and DMAP $(10 \mathrm{mg})$ in $\mathrm{CH}_{2} \mathrm{Cl}_{2}(15 \mathrm{~mL})$ was added $\mathrm{Et}_{3} \mathrm{~N}(0.76 \mathrm{~mL}, 5.2 \mathrm{mmol})$ dropwise over 10min, and the mixture was stirred at rt for 4 h, diluted with $\mathrm{CH}_{2} \mathrm{Cl}_{2}(30 \mathrm{~mL})$, washed with saturated aq. $\mathrm{NaHCO}_{3}$ and brine, dried $\left(\mathrm{Na}_{2} \mathrm{SO}_{4}\right)$, filtered and concentrated under reduced pressure. The residue was purified by silica gel flash column chromatography (EtOAc/Hexanes=1/2) to afford 14 (607 mg, 88\%) as a white solid.

Mp. $112-113{ }^{\circ} \mathrm{C} ;[\alpha]_{\mathrm{D}}^{23}-41.3\left(c 1.04, \mathrm{CHCl}_{3}\right) ;{ }^{1} \mathrm{H}$ NMR $\left(\mathrm{CDCl}_{3}\right) \delta 7.74(\mathrm{~d}, 2 \mathrm{H}, J=8.9 \mathrm{~Hz})$, 7.39-7.25 (m, 5H), 7.11 (d, 1H, $J=8.9 \mathrm{~Hz}$ ), 6.90 (d, 2H, $J=8.9 \mathrm{~Hz}$ ), 5.11 (dd, 1H, $J=7.9$, 3.7 $\mathrm{Hz}$ ), 4.06-3.95 (m, 3H), 3.83 (s, 3H), 2.56 (br s, 1H), 1.85-1.63 (m, 2H), 1.58-1.49 (m, 1H), 1.28-1.15 (m, 1H), $1.12(\mathrm{~s}, 9 \mathrm{H}) ;{ }^{13} \mathrm{C}$ NMR $\left(\mathrm{CDCl}_{3}\right) \delta 178.7,166.5,162.2,138.0,128.9,128.6$, 127.9, 127.8, 126.4, 113.7, 73.6, 63.8, 58.2, 55.4, 38.7, 30.2, 27.1, 25.2. ESI-MS $m / z 414.2(\mathrm{M}+$ $\mathrm{H}^{+}$); HR-ESI-MS $m / z$ Calcd for $\mathrm{C}_{24} \mathrm{H}_{32} \mathrm{NO}_{5} 414.2280$, Found 414.2308.

\section{Compound 19:}

A suspension of 16 (315 mg, $0.79 \mathrm{mmol})$ and $20 \% \mathrm{Pd}(\mathrm{OH})_{2} / \mathrm{C}(280 \mathrm{mg})$ in $\mathrm{MeOH}(5 \mathrm{~mL})$ was stirred under $\mathrm{H}_{2}$ atmosphere at rt for $2 \mathrm{~h}, \mathrm{Boc}_{2} \mathrm{O}$ (259 mg, $1.90 \mathrm{mmol}$ ) was then added, and the mixture was stirred for an additional 3h, filtered through celite, and concentrated under reduced pressure. The residue was purified by silica gel flash column chromatography (EtOAc/Hexanes=1/4) to afford $\mathbf{1 9}(236 \mathrm{mg}, 79 \%)$ as a white solid.

Mp. 68-69 ${ }^{\circ} \mathrm{C} ;[\alpha]_{\mathrm{D}}{ }^{23}+7.8\left(\mathrm{c} 0.97, \mathrm{CHCl}_{3}\right) ;{ }^{1} \mathrm{H}$ NMR $\left(\mathrm{CDCl}_{3}\right) \delta 7.38-7.22(\mathrm{~m}, 5 \mathrm{H}), 5.37$ (br m, 1H), 4.64 (br m, 1H), 4.05 (t, 2H, $J=6.3 \mathrm{~Hz}$ ), 3.84 (br m, 1H), 2.24 (br s, 1H), 1.90-1.48 (m, 4H), 1.42 (br s, 9H), 1.15 (s, 9H); ${ }^{13} \mathrm{C} \mathrm{NMR}\left(\mathrm{CDCl}_{3}\right) \delta 178.6,156.1,140.5,128.8,127.6,126.5,79.8$, 74.8, 64.0, 58.9, 38.7, 30.2, 28.3, 27.1, 25.0. ESI-MS $m / z$ 402.2 (M + $\left.\mathrm{Na}^{+}\right)$; HR-ESI-MS $\mathrm{m} / \mathrm{z}$ Calcd for $\mathrm{C}_{21} \mathrm{H}_{33} \mathrm{NO}_{5} \mathrm{Na}$ 402.2256, Found 402.2237.

\section{Compound 20:}

To a cooled $\left(0^{\circ} \mathrm{C}\right)$ solution of 19 (180 mg, $\left.0.47 \mathrm{mmol}\right)$, 3,5- $\left(\mathrm{CF}_{3}\right)_{2} \mathrm{C}_{6} \mathrm{H}_{3} \mathrm{CH}_{2} \mathrm{Br}$ (284 mg, 0.94 mmol) and TBAI (260 mg, $0.71 \mathrm{mmol})$ in dry DMF under Ar was added $\mathrm{NaH}(20 \mathrm{mg}, 60 \%$ dispersion in mineral oil, $0.50 \mathrm{mmol}$ ) in two portions over $5 \mathrm{~min}$, stirring was continued for $30 \mathrm{~min}$, and the reaction was quenched with aq. $\mathrm{NH}_{4} \mathrm{Cl}$ followed by extraction with ether $(3 \times 15 \mathrm{~mL}$ ). The combined organic layer was washed with water and brine, dried $\left(\mathrm{Na}_{2} \mathrm{SO}_{4}\right)$, filtered and concentrated under reduced pressure. The residue was purified by silica gel flash column chromatography (EtOAc/Hexanes=1/12) to afford 20 (238 $\mathrm{mg}, 83 \%$ ) as a white solid.

Mp. 61-62 ${ }^{\circ} \mathrm{C} ;[\alpha]_{\mathrm{D}}^{22}+14.1$ (c 0.96, $\left.\mathrm{CHCl}_{3}\right) ;{ }^{1} \mathrm{H} \mathrm{NMR}\left(\mathrm{CDCl}_{3}\right) \delta 7.76$ (br s, $\left.1 \mathrm{H}\right), 7.52$ (br s, 2H), 7.40-7.25 (m, 5H), 5.38 (br m, 1H), 4.86 (br m, 1H), 4.50-4.11 (AB, 2H, $\left.J_{\mathrm{AB}}=11.7 \mathrm{~Hz}\right), 4.10$ (t, $1 \mathrm{H}, J=6.3 \mathrm{~Hz}$ ), 3.71 (br m, 1H), 1.84-1.62 (m, 4H), 1.42 (br s, 9H), 1.20 (s, 9H); ${ }^{13} \mathrm{C} \mathrm{NMR}$ $\left(\mathrm{CDCl}_{3}\right) \delta 178.5,155.6,140.9,140.4,131.6(\mathrm{q}, J=32.9 \mathrm{~Hz}), 128.5,127.6,127.4,126.2,123.2$ (q, $J=271 \mathrm{~Hz}), 121.6,83.5,79.8,71.3,63.8,56.4,38.7,29.7,28.3$, 27.2, 25.1. ESI-MS $m / z$ 628.3 (M $+\mathrm{Na}^{+}$); HR-ESI-MS $m / z$ Calcd for $\mathrm{C}_{30} \mathrm{H}_{37} \mathrm{~F}_{6} \mathrm{NO}_{5} \mathrm{Na}$ 628.2474, Found 628.2426. 


\section{Compound 21:}

To a solution of 20 (185 mg, $0.31 \mathrm{mmol}$ ) in $\mathrm{MeOH}(5 \mathrm{~mL}$ ) under Ar was added 30\% NaOMe in $\mathrm{MeOH}(0.11 \mathrm{~mL}, 0.62 \mathrm{mmol})$, the solution was stirred at $\mathrm{rt}$ for $4 \mathrm{~h}$, quenched by water, and extracted with $\mathrm{Et}_{2} \mathrm{O}(3 \times 15 \mathrm{~mL})$. The combined organic phase was washed with brine, dried $\left(\mathrm{Na}_{2} \mathrm{SO}_{4}\right)$, filtered and concentrated under reduced pressure to afford the crude product which was used in the next step without further purification.

To a cooled $\left(0^{\circ} \mathrm{C}\right)$ solution of the above crude alcohol and $\mathrm{Et}_{3} \mathrm{~N}(0.07 \mathrm{~mL}, 0.5 \mathrm{mmol})$ in $\mathrm{CH}_{2} \mathrm{Cl}_{2}(10 \mathrm{~mL})$ was added dropwise $\mathrm{MsCl}(0.03 \mathrm{~mL}, 0.45 \mathrm{mmol})$, and the mixture was stirred at $0^{\circ} \mathrm{C}$ for $30 \mathrm{~min}$, diluted with $\mathrm{Et}_{2} \mathrm{O}(30 \mathrm{~mL})$, and washed successively with $1 \mathrm{M} \mathrm{HCl}$, saturated aq. $\mathrm{NaHCO}_{3}$ and brine, dried $\left(\mathrm{Na}_{2} \mathrm{SO}_{4}\right)$, filtered and concentrated under reduced pressure. The residue was dissolved in THF (10 mL) under Ar, $\mathrm{NaH}$ (50 mg, 60\% dispersion in mineral oil, $1.25 \mathrm{mmol}$ ) was added and the mixture was stirred at rt for 2 days, quenched by saturated aq. $\mathrm{NH}_{4} \mathrm{Cl}$, extracted with $\mathrm{Et}_{2} \mathrm{O}(3 \times 15 \mathrm{~mL})$, and washed with brine, dried $\left(\mathrm{Na}_{2} \mathrm{SO}_{4}\right)$, filtered and concentrated under reduced pressure. The residue was purified by silica gel flash column chromatography (EtOAc/Hexanes=1/16) to afford 21 (118 mg, 77\%) as a colorless oil.

$[\alpha]_{\mathrm{D}}{ }^{22}+45.1\left(\mathrm{c} \mathrm{0.68}, \mathrm{CHCl}_{3}\right) ;{ }^{1} \mathrm{H}$ NMR $\left(\mathrm{CDCl}_{3}\right) \delta 7.77$ (br s, $\left.1 \mathrm{H}\right), 7.71$ (br s, 2H), 7.56 (br s, $1 \mathrm{H}$ ), 7.54 (br s, 1H), 7.36-7.23 (m, 3H), 5.69 (br s, $1 \mathrm{H}$ ), 4.73 (AB, 2H, $J_{\mathrm{AB}}=12.9 \mathrm{~Hz}$ ), 3.95 (dd, $1 \mathrm{H}, J=$ 12.9, 3.6 Hz), 3.94-3.84 (m, 1H), 2.76 (ddd, $1 \mathrm{H}, J=12.6,12.6,3.5 \mathrm{~Hz}$ ), 2.04-1.94 (m, 2H), 1.78-1.58 (m, 2H), 1.46 (s, 9H); ${ }^{13} \mathrm{C}$ NMR $\left(\mathrm{CDCl}_{3}\right) \delta 155.2,141.0,138.0,131.6(\mathrm{q}, J=32.8 \mathrm{~Hz})$, 128.3, 127.2, 127.0, 123.2 (q, $J=271 \mathrm{~Hz}), 121.4$ (m), 80.1, 78.7, 69.1, 55.5, 39.2, 28.4, 25.8, 24.1. ESI-MS $m / z 526.1\left(\mathrm{M}+\mathrm{Na}^{+}\right)$; HR-ESI-MS $m / z$ Calcd for $\mathrm{C}_{25} \mathrm{H}_{28} \mathrm{~F}_{6} \mathrm{NO}_{3}\left(\mathrm{M}+\mathrm{H}^{+}\right)$504.1973, Found 504.1949. 


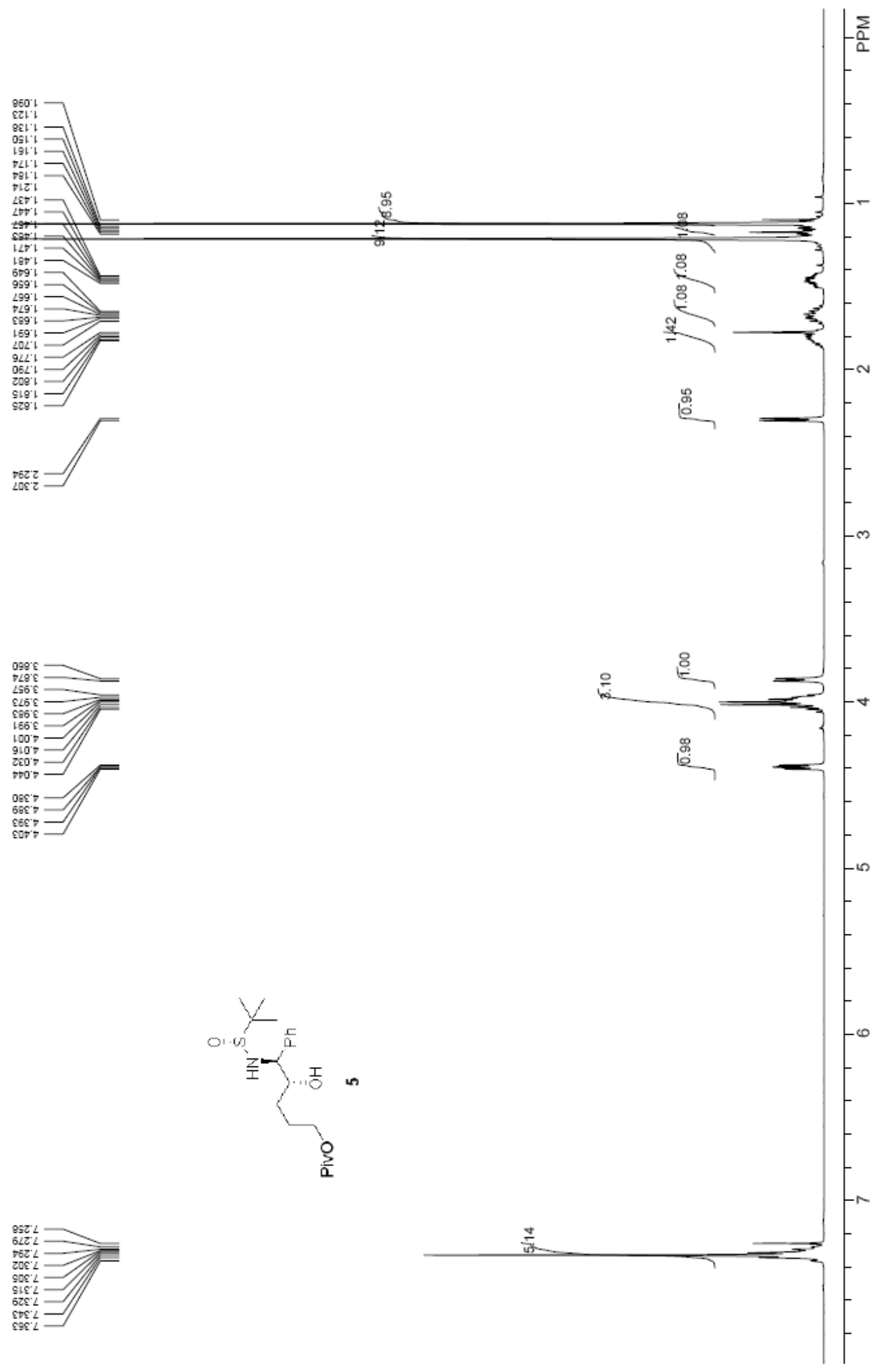


$999 \cdot 2 z-$

681.52

666.62

$9 \$ 9 \cdot 9 \varepsilon$

$082 \cdot 9$

$682 \cdot 29$
$\angle 26.89$

$\varepsilon s 0^{\circ} \varepsilon L$

089.92

$266^{\circ} 9 L$
ZIE. $2 L-$

$95 I^{\circ} 821-$
$065 \cdot 821-$

$6 \angle 6+\angle E T$

$6 \mathrm{IS} \cdot 8<\mathrm{I}$

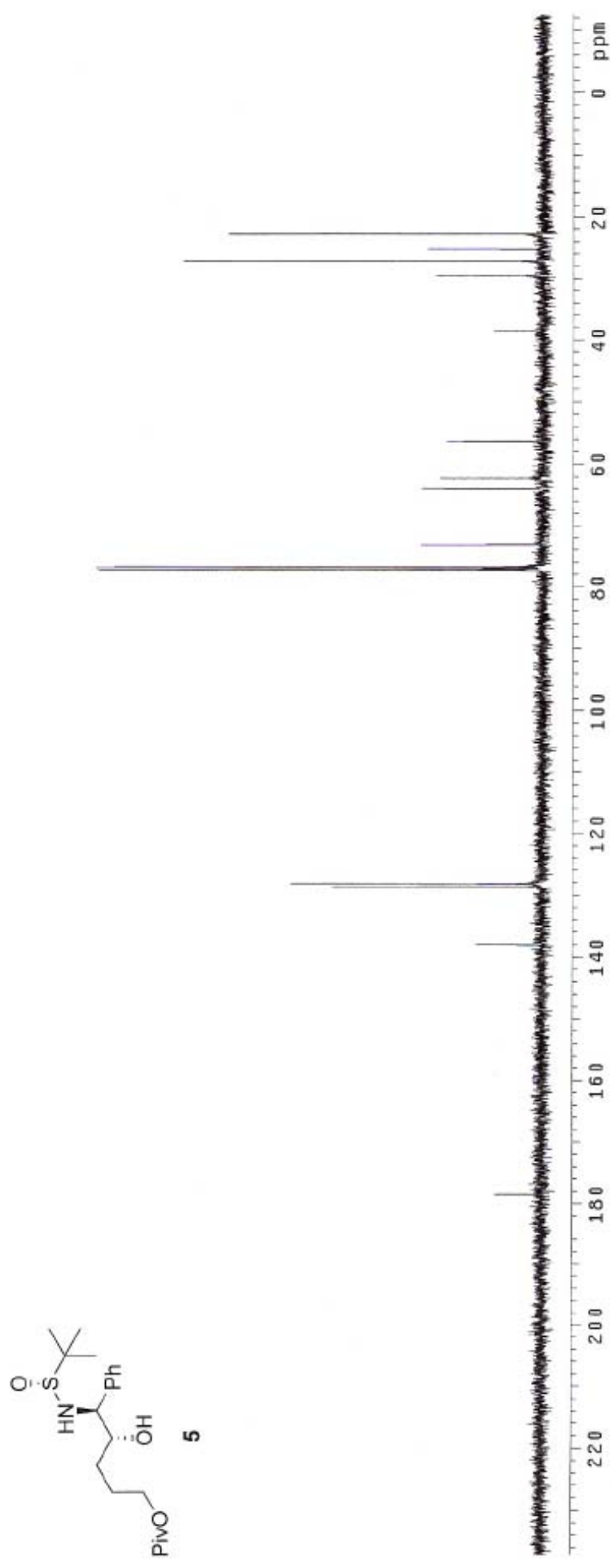




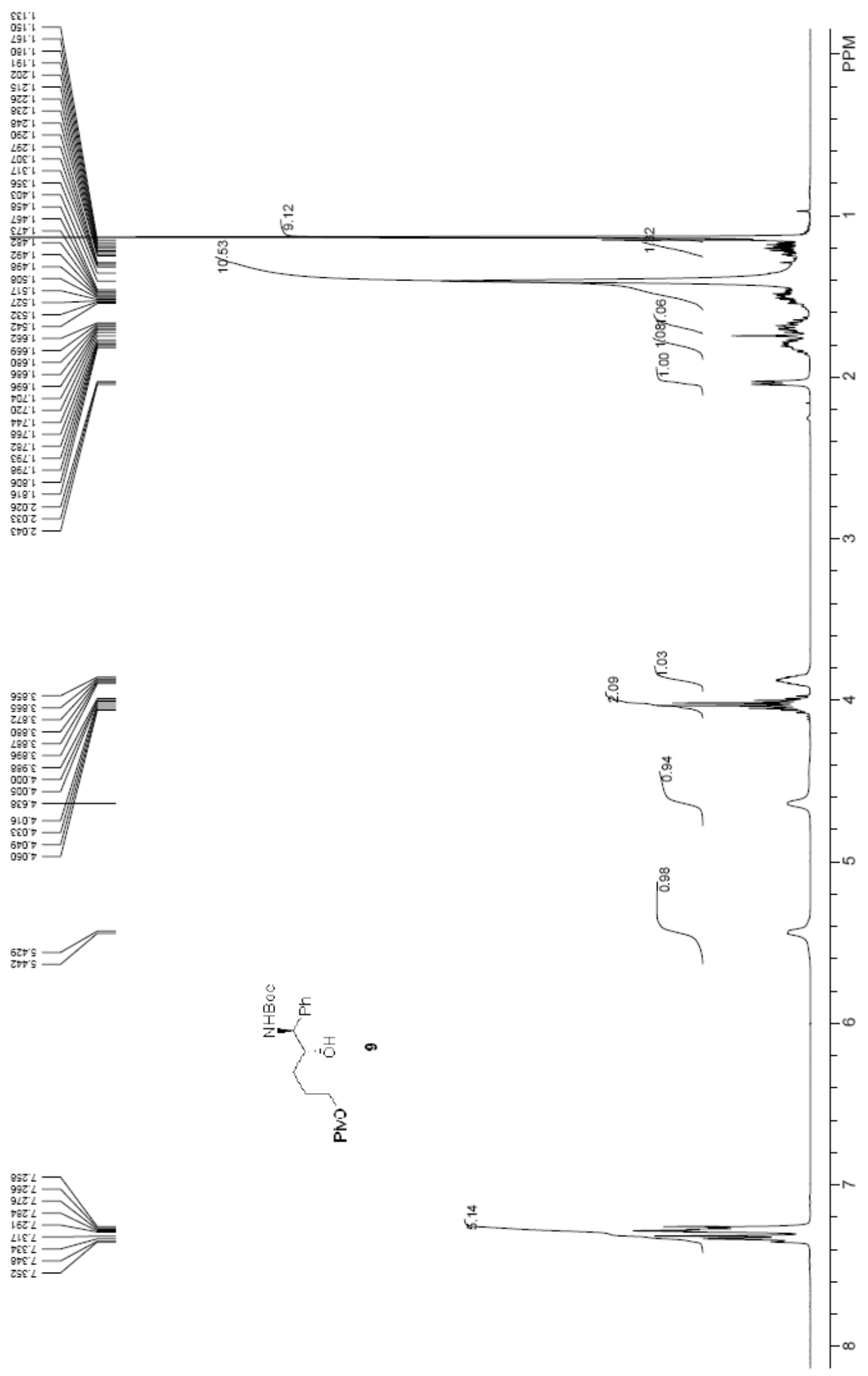


$80 \mathrm{~T} \cdot 5 \mathrm{Z}$
$20 \mathrm{~T} \cdot \mathrm{LZ}$

$905^{\circ} 82$
$626.62-$

$699^{\circ} 9 \varepsilon$

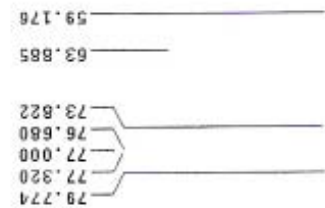

$009^{\circ} \angle Z \mathrm{I}$

DI $L^{\circ} \angle Z I-$
$\angle E S^{\circ} \mathrm{BZT}-$

$90 S^{\prime}$ SST-

$819.8<1$

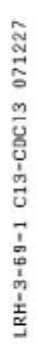

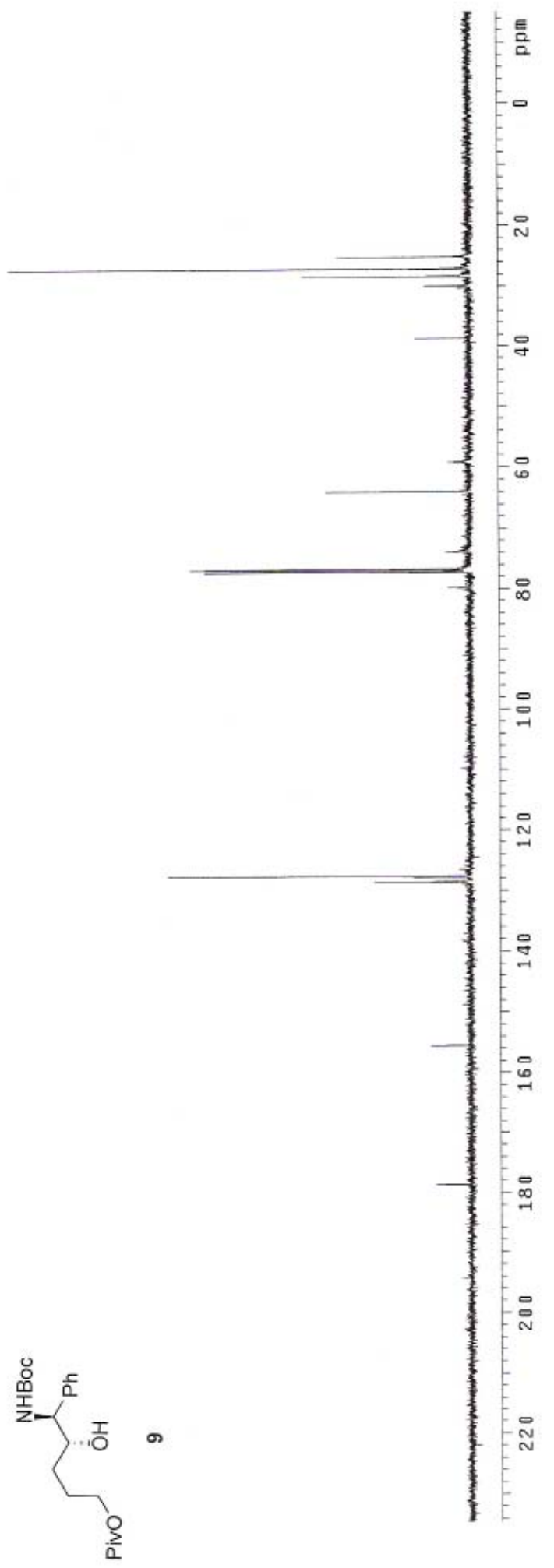




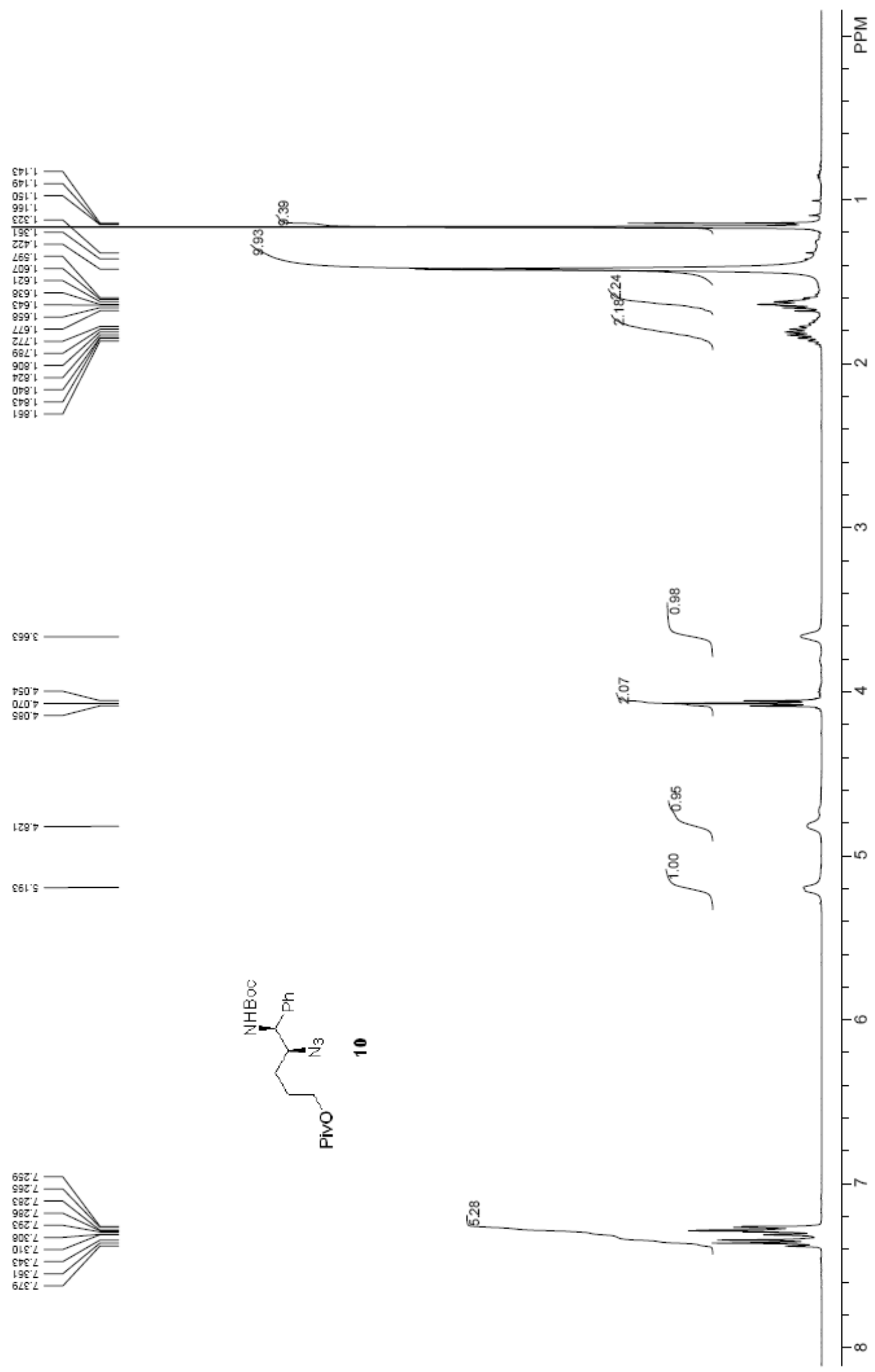


$2<0 \cdot s z$

$06 \mathrm{I} \cdot 2 \mathrm{Z}-$

$5 \angle 2 \cdot 8 Z$

$002 \cdot 0$

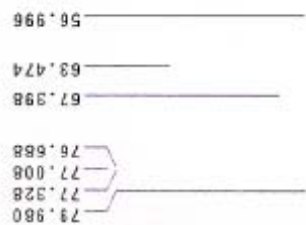

$968^{\circ} 92 \mathrm{~T}$

522.821

$326 \cdot 68 \mathrm{~T}$

$\angle O E \cdot 5 S T$

$996 \cdot B 2 I$

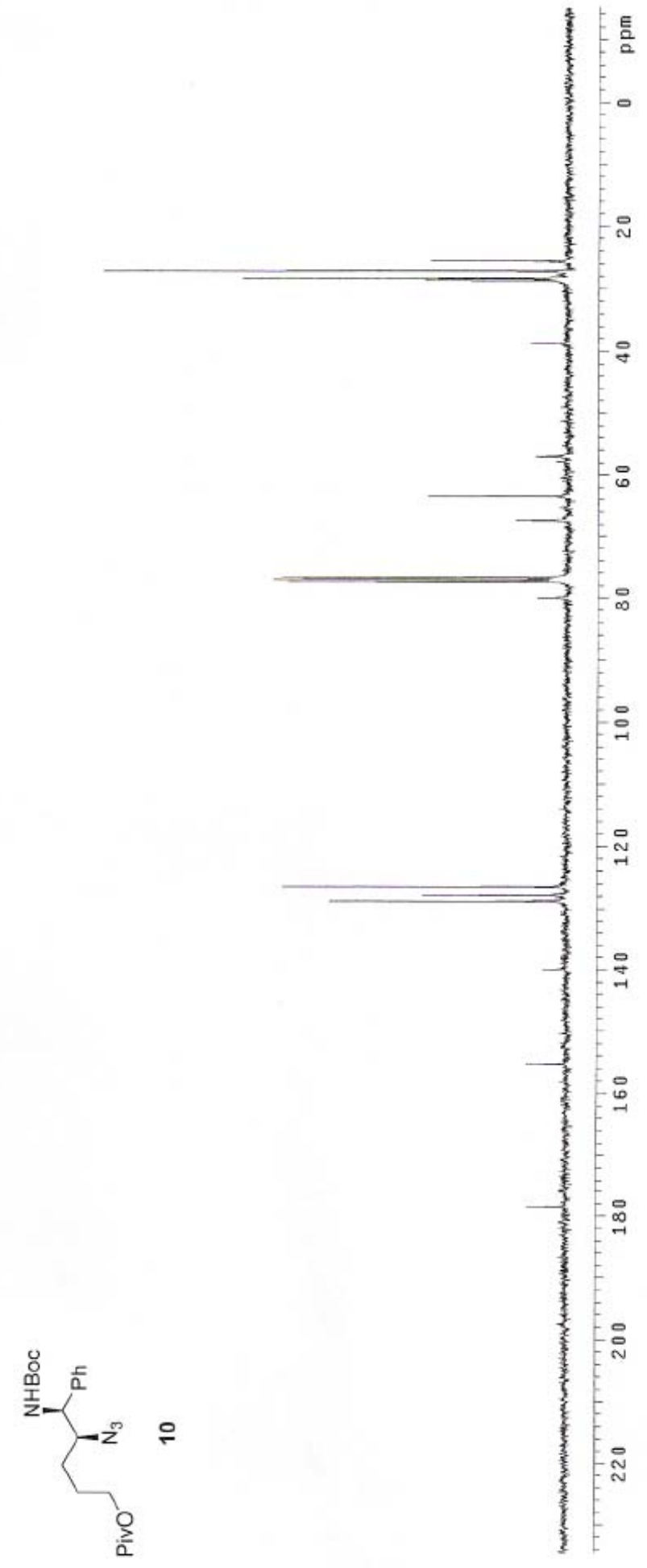




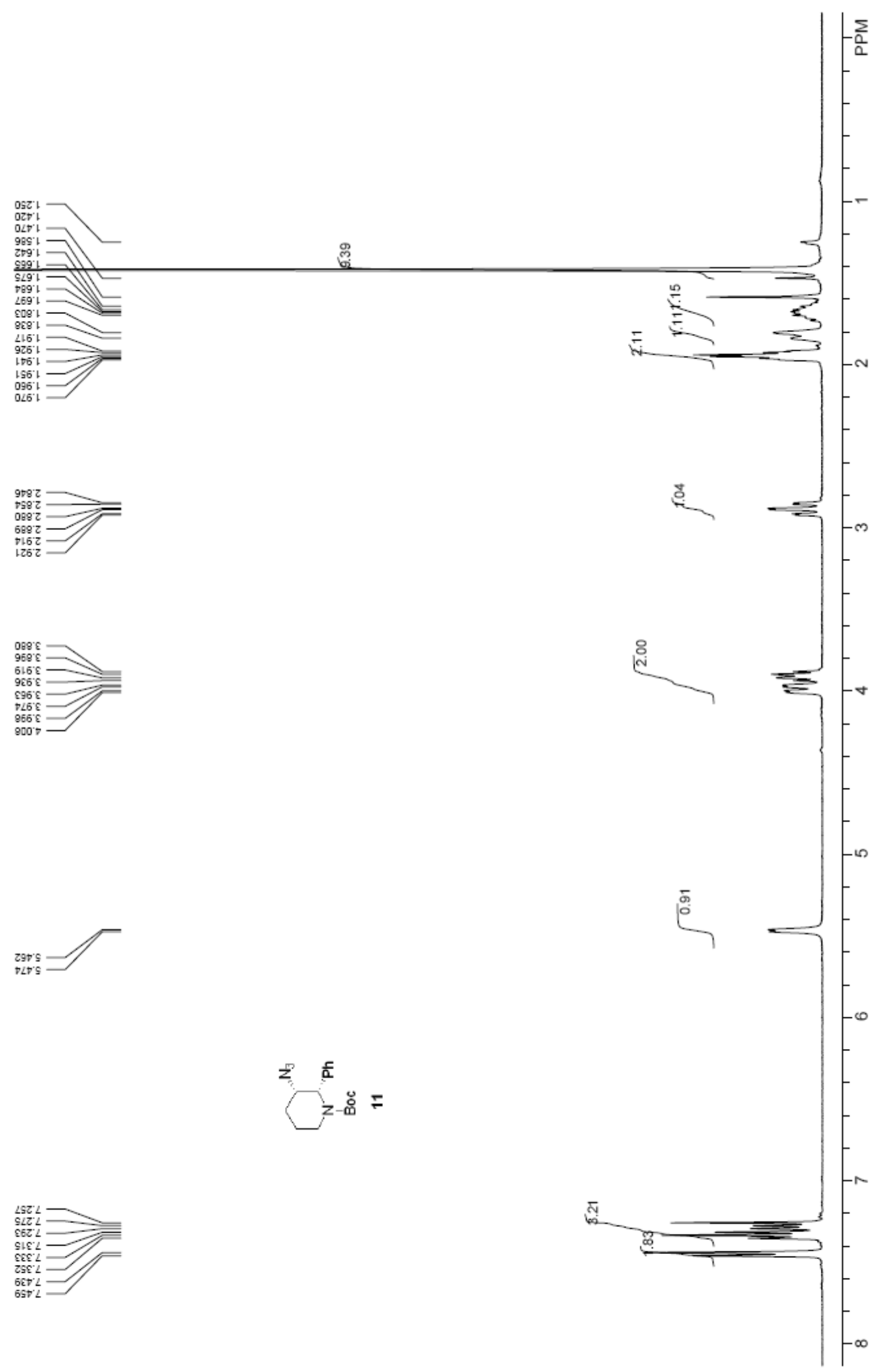


$706 \varepsilon z-\square$
$6897 z-$
89287

$\varepsilon 206 \varepsilon$

S2S'9s

$\angle S S_{09}$

$099.9 L$
$8869 L$

${ }_{61 Z}^{86 Z} \angle 2$

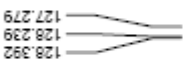

$7 / 9<\varepsilon 1-$

عร6 จst -

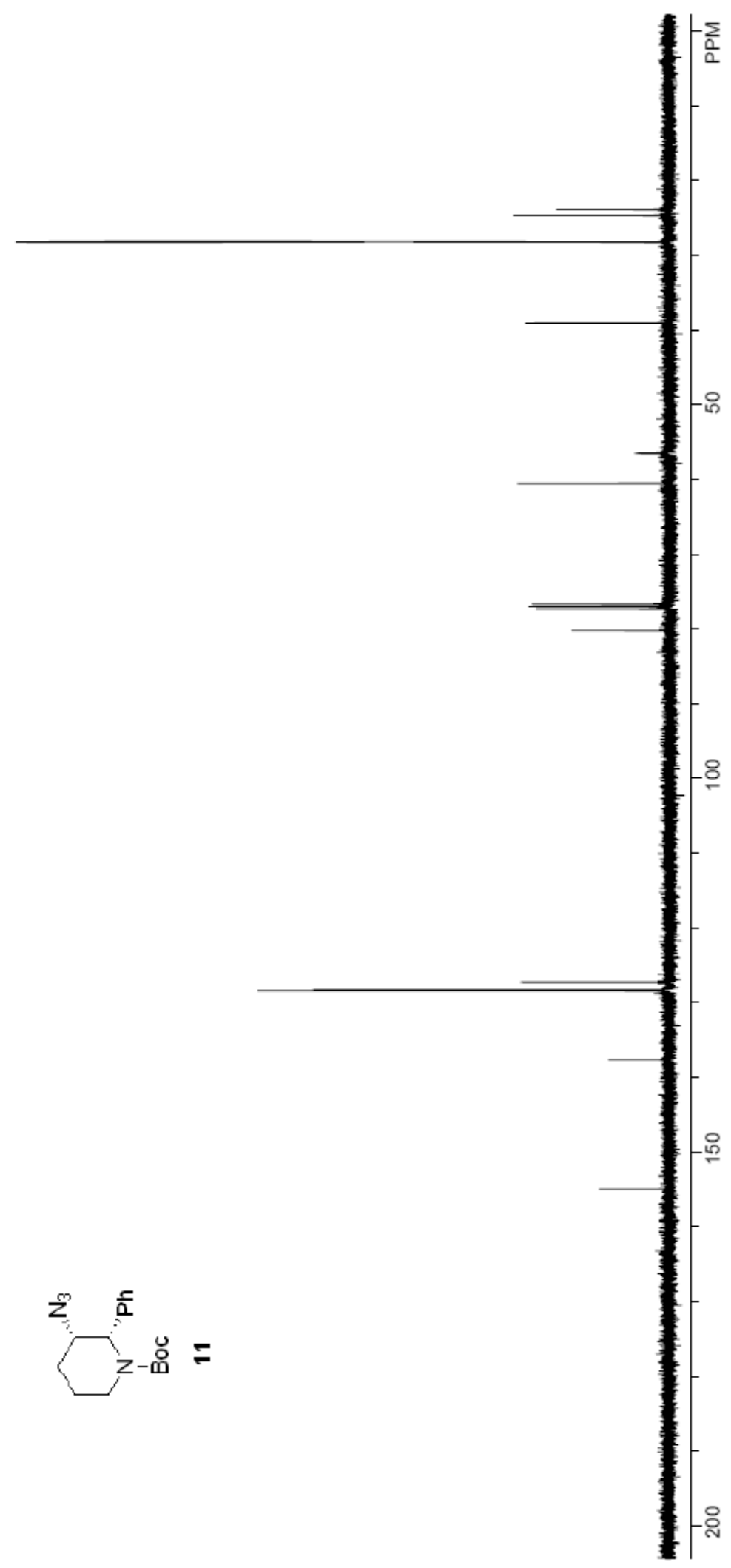




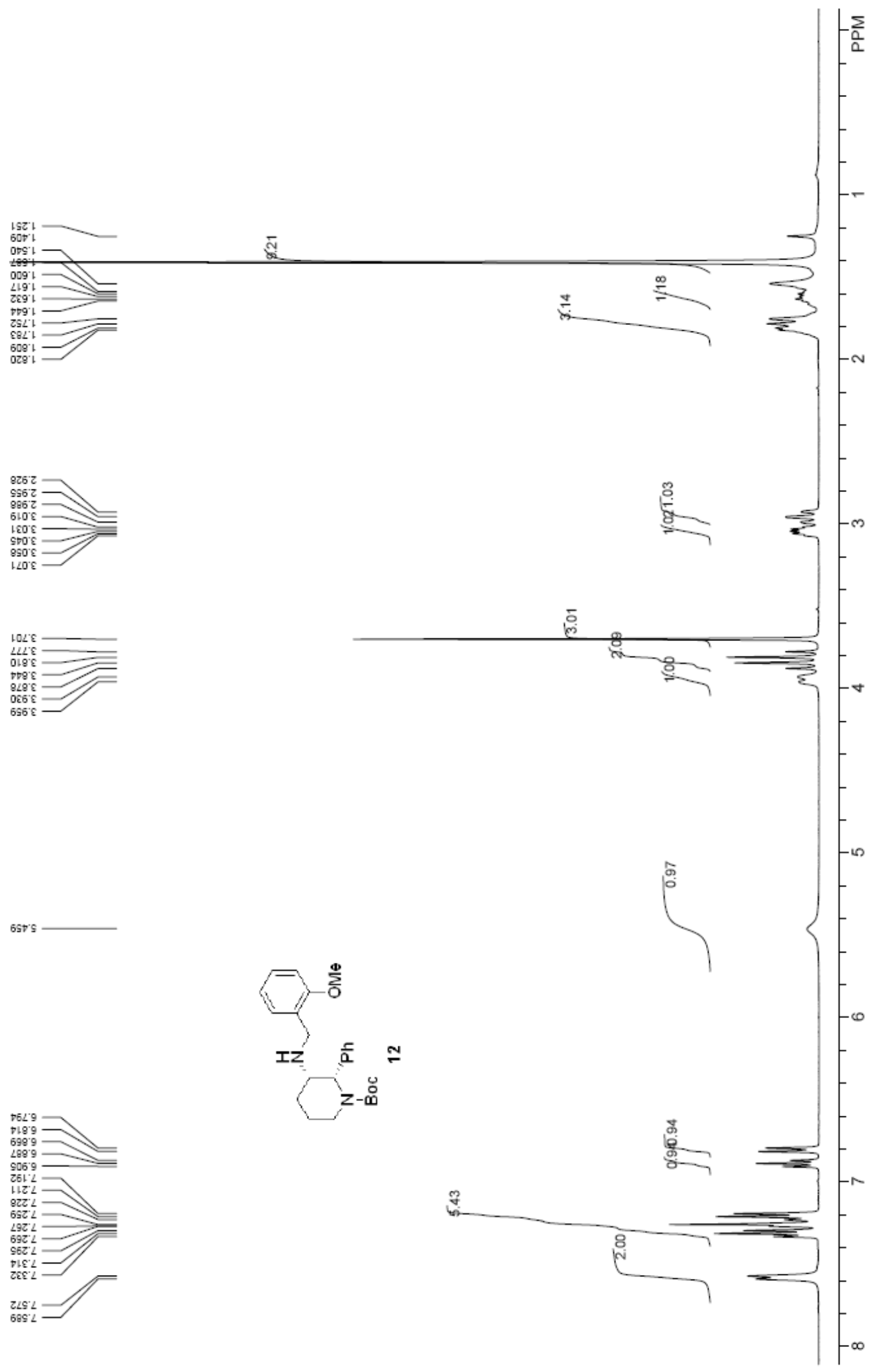


$S 0 \varepsilon^{\circ} \cdot 0 z-$
$8 S L \cdot 9 z=$
$Z B E \cdot B z-$
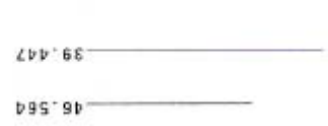

$\angle 00^{\circ} \mathrm{SS}$
$6 \angle \mathrm{I}^{\circ} \angle \mathrm{S}$

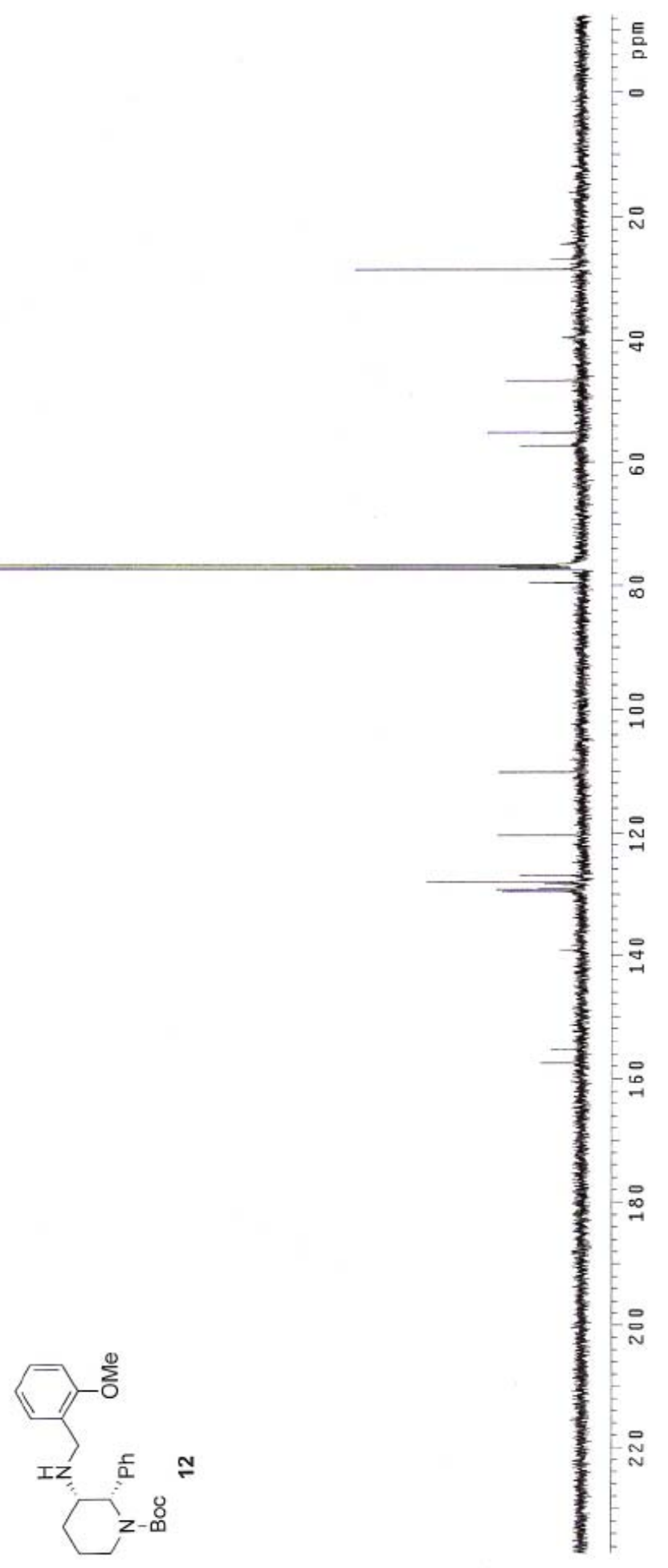

$599 \cdot 9 l-$
$1<6.9 l-$

$\begin{array}{ll}\angle 62 & \angle 2 \\ 895^{\circ}-6 L & -\end{array}$

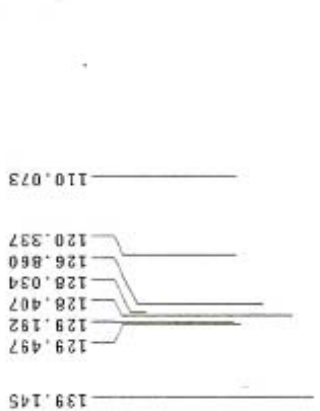

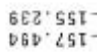

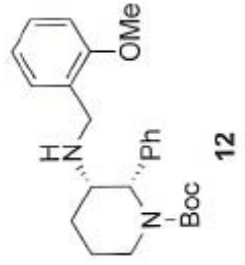

$\stackrel{N}{N}$ 

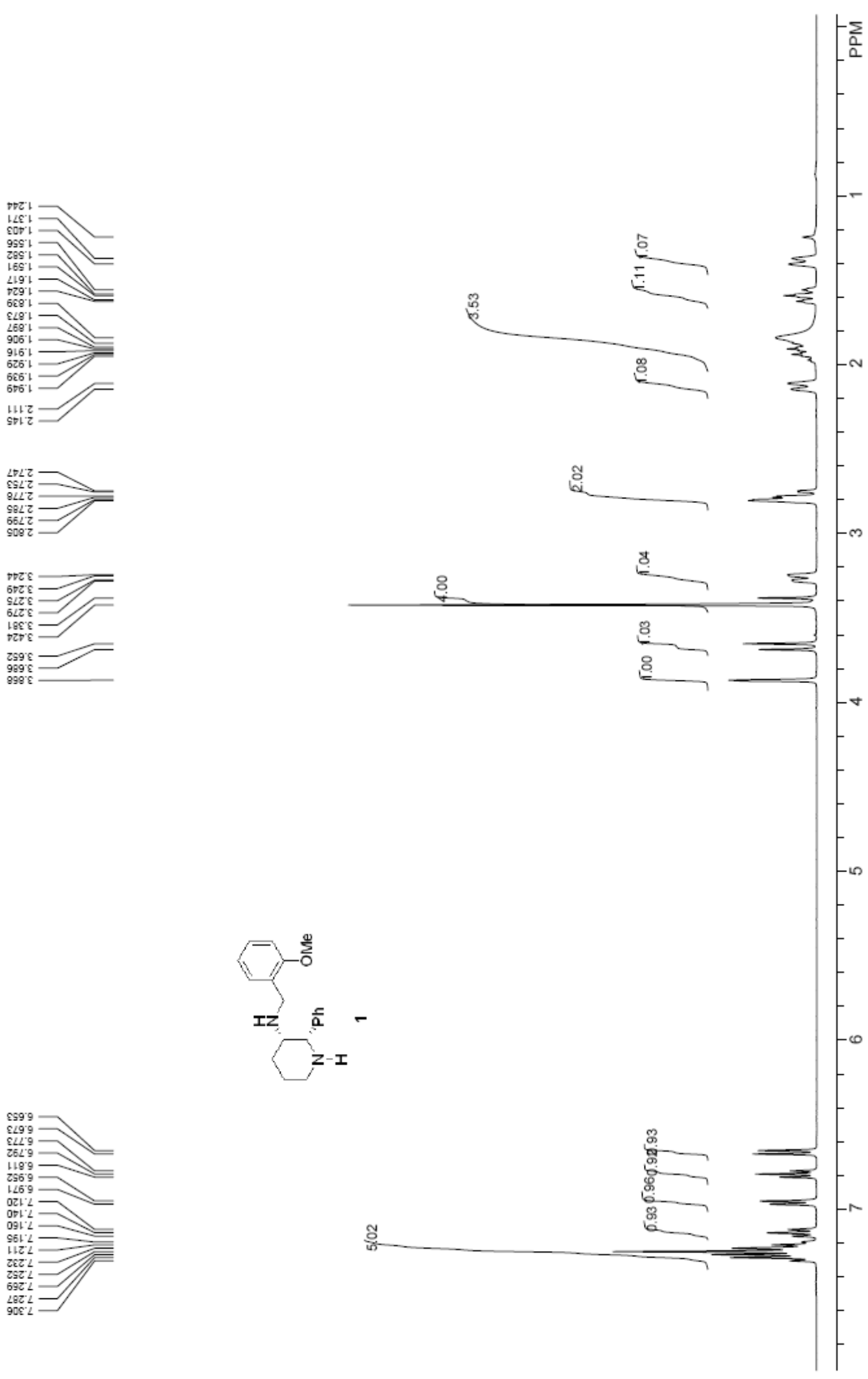

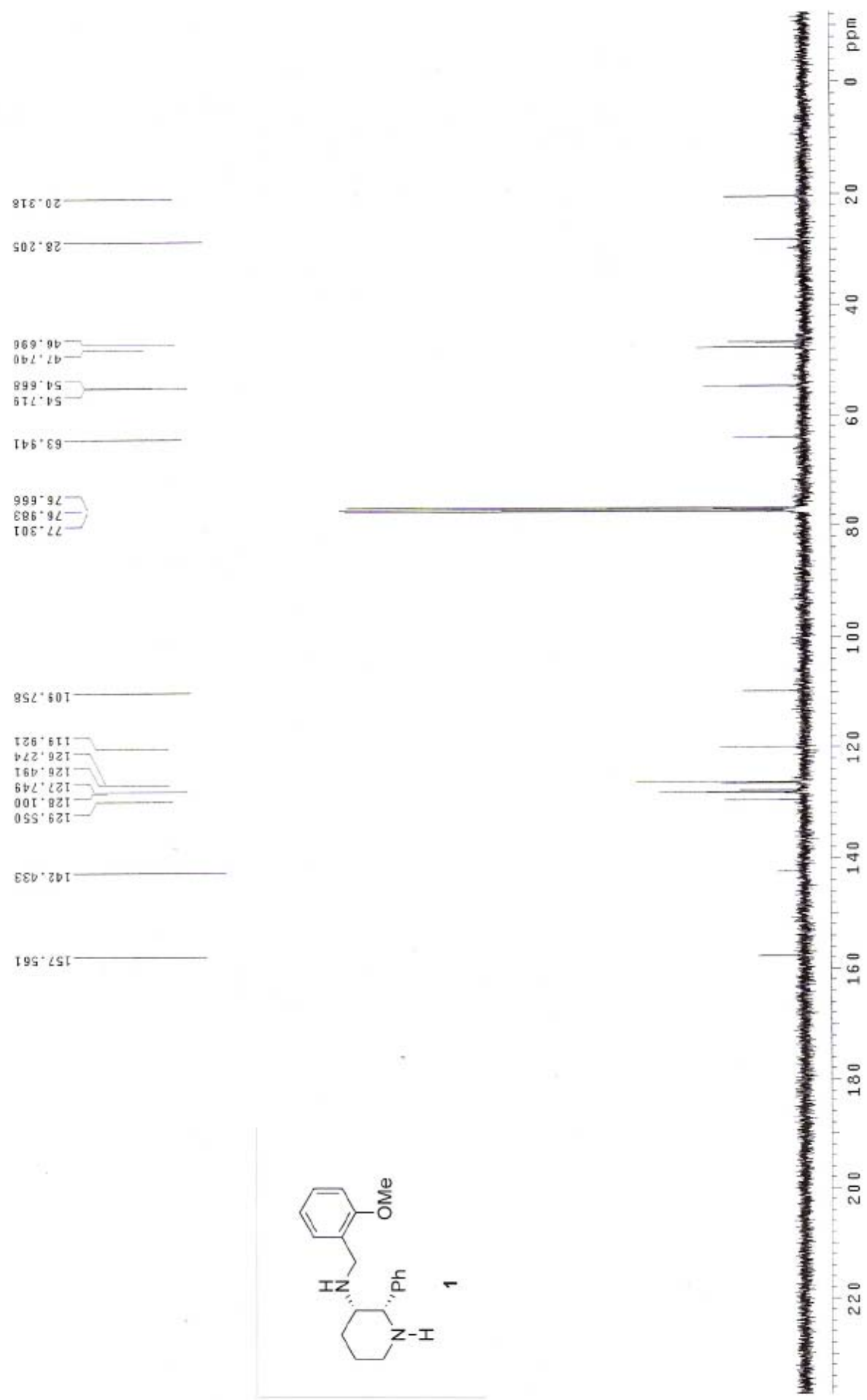


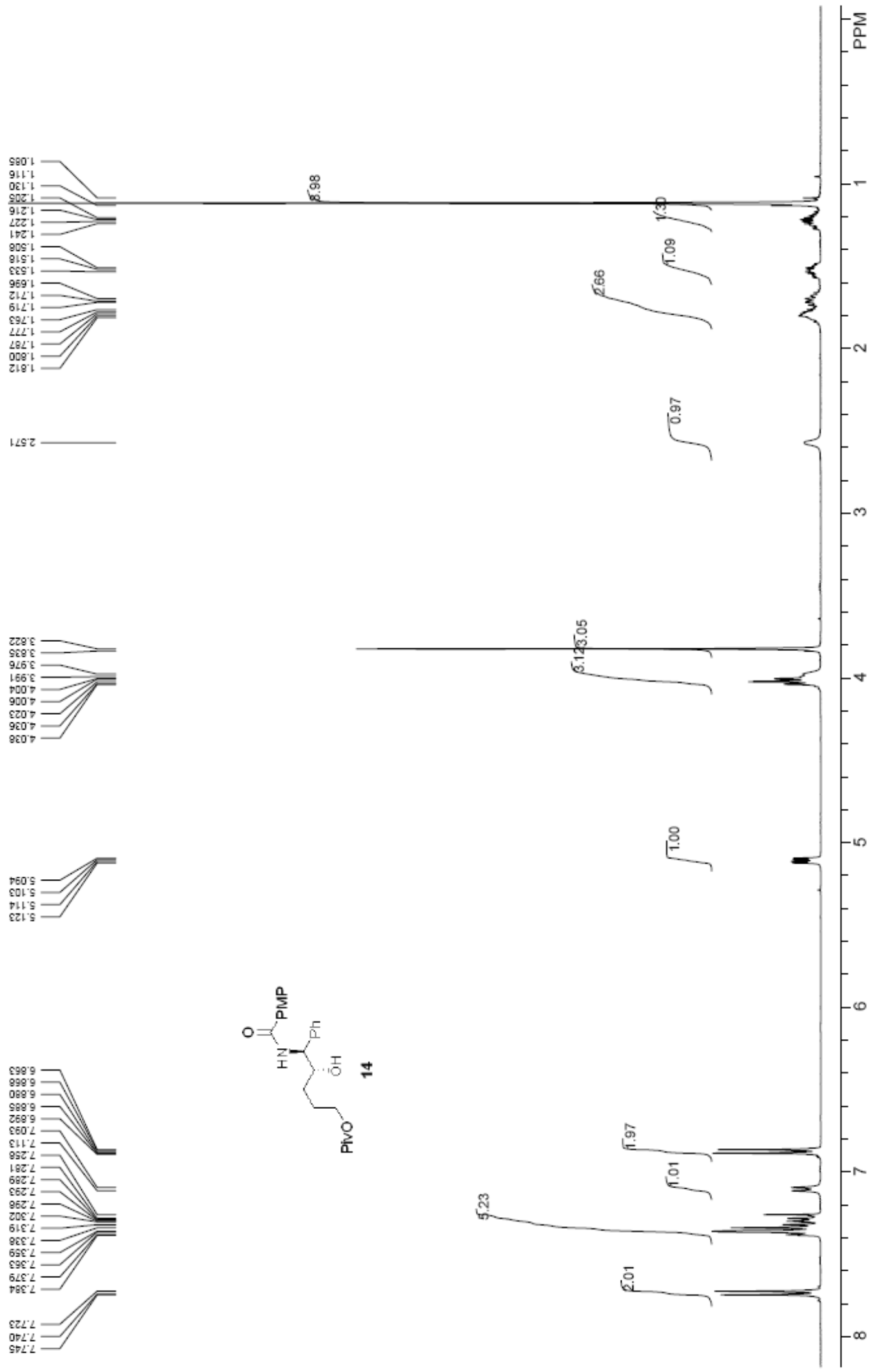


$96 \mathrm{~T} \cdot 52-$
$980.22-$

a SI. 0

$699^{\circ} \mathrm{BE}$

ELE. 55

$825 \cdot 8$

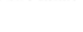

S $9^{\circ} \varepsilon<-$

$569.92-$

$800^{\circ} \mathrm{LL}-$

$269.811-$

IIt. $92 \mathrm{II}$

$\checkmark \angle B \cdot \angle 2 \mathrm{I}=$

$865.821=$

$956 \cdot \angle \varepsilon I$

osz $z 91$

zह5.99I

$6 \angle 9^{\circ} 8 \angle I$

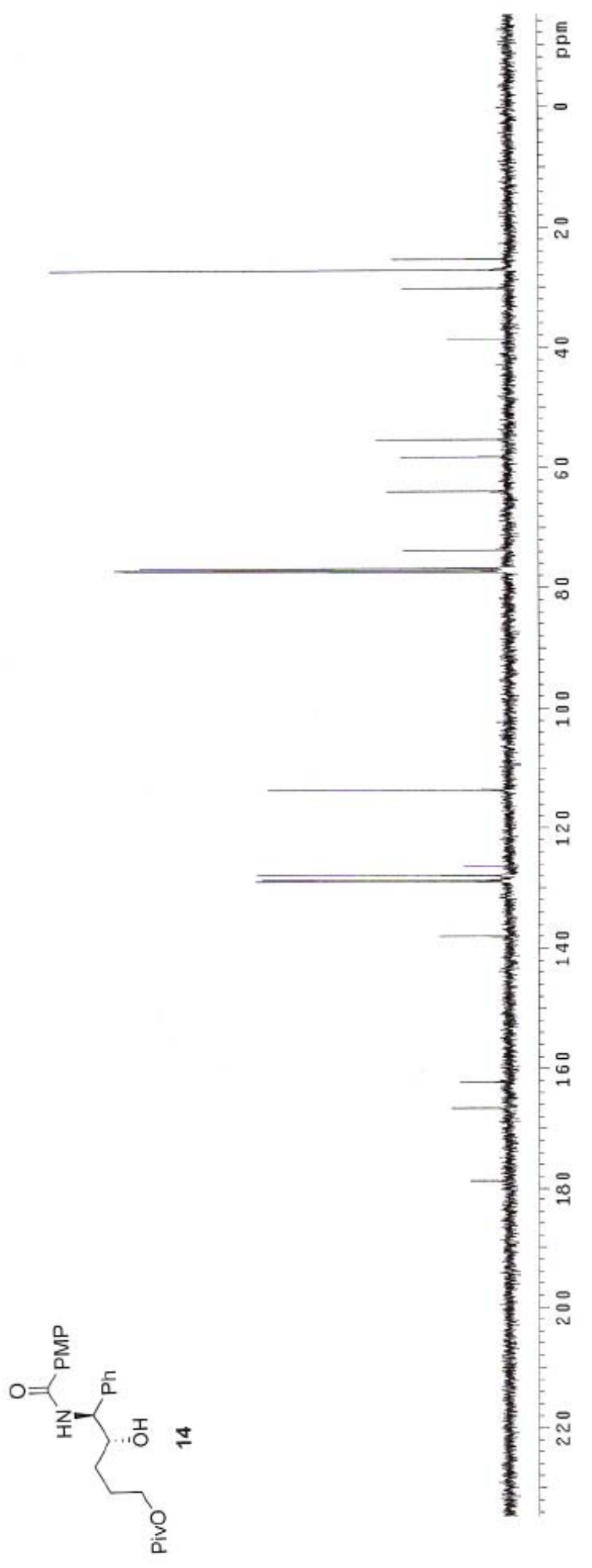




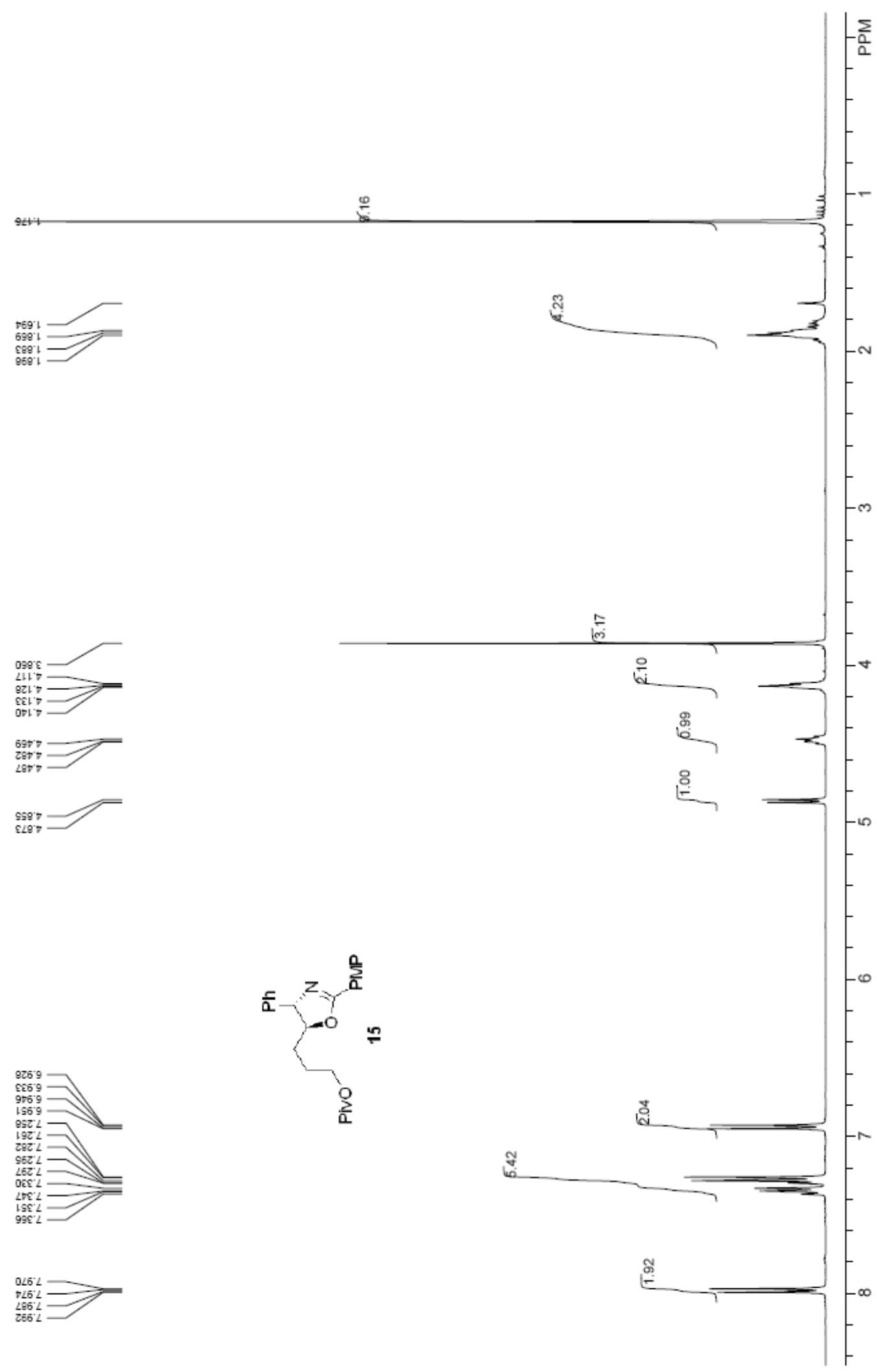


$9 z 8^{\circ} \cdot 2 z$
$56 I^{\circ} \cdot 2 z$

$808^{\circ}$ Ts

$\varepsilon น L B E$

ZSE.SS

$05 \angle \cdot 89$

$869.52-$

659.92
226.92

$v 0 z \cdot \angle 8$

$\varepsilon Z L^{\circ} \varepsilon I-$

IVT.0ZI

$299.92 \mathrm{I}$

$9 E 2 \cdot \mathrm{BLI}-$

I LI $08 \mathrm{I}$

$095^{\circ} Z \mathrm{DF}-$

$5<z^{\circ} 29 t-$
$962.89 t-$

$b \angle t \cdot 8 \angle I-$

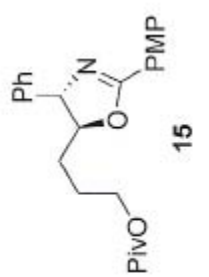

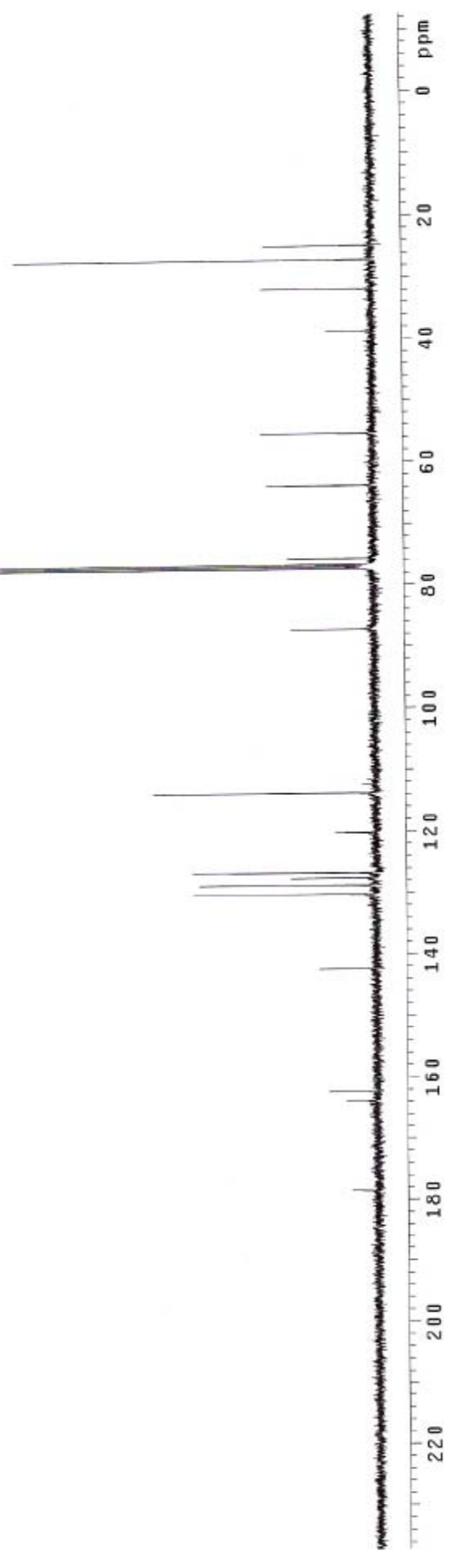




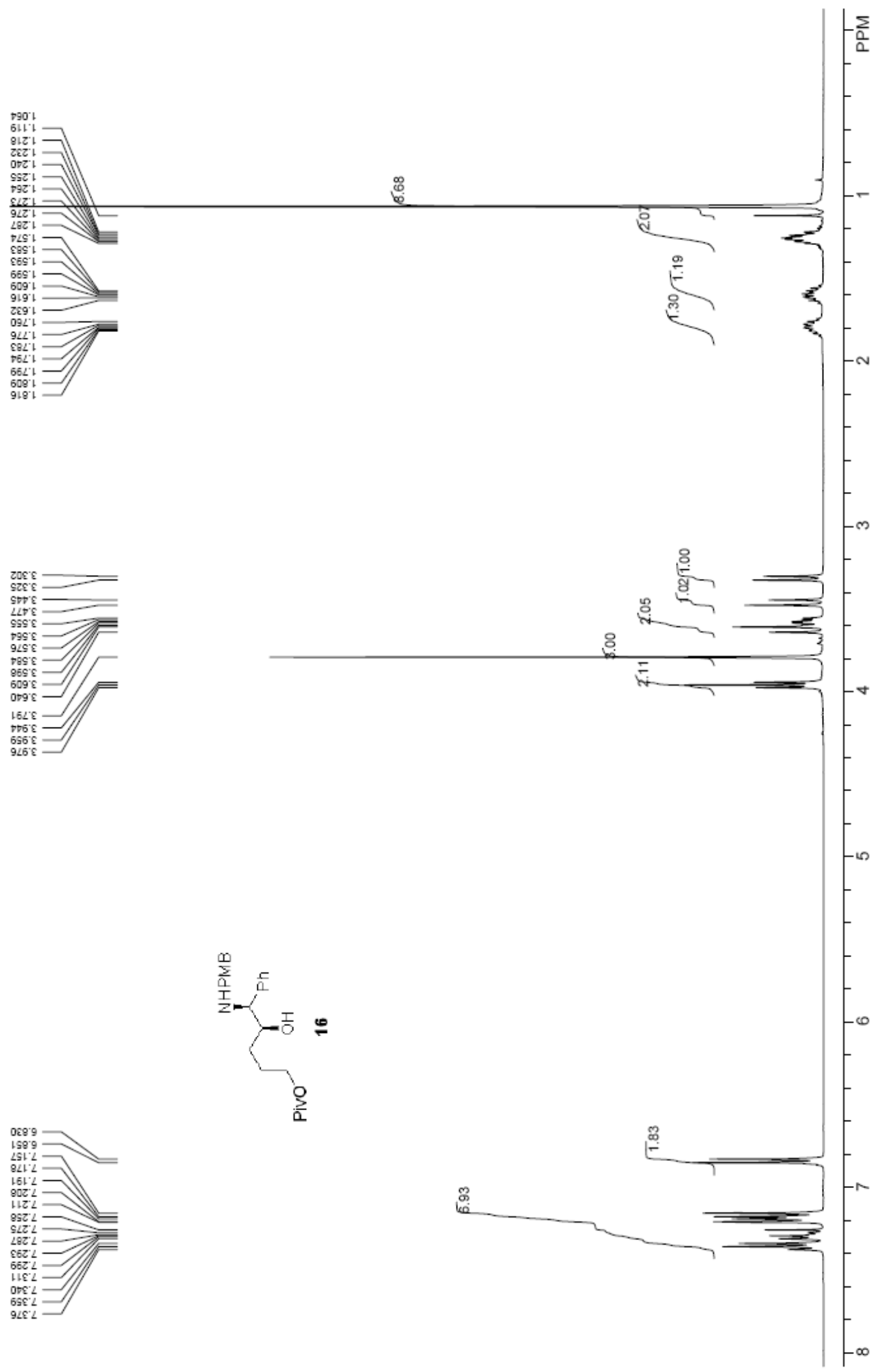




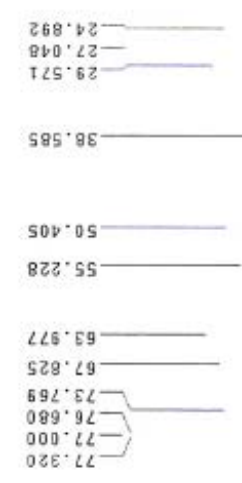

692. EIT -

$005 \cdot 221$

$9 \angle 9^{\circ} \cdot 2 Z \mathrm{I}$
$80 L^{\circ} \cdot 8 \mathrm{II}$

$088.621-$

$829^{\circ} 06 \mathrm{~T}$

889.891

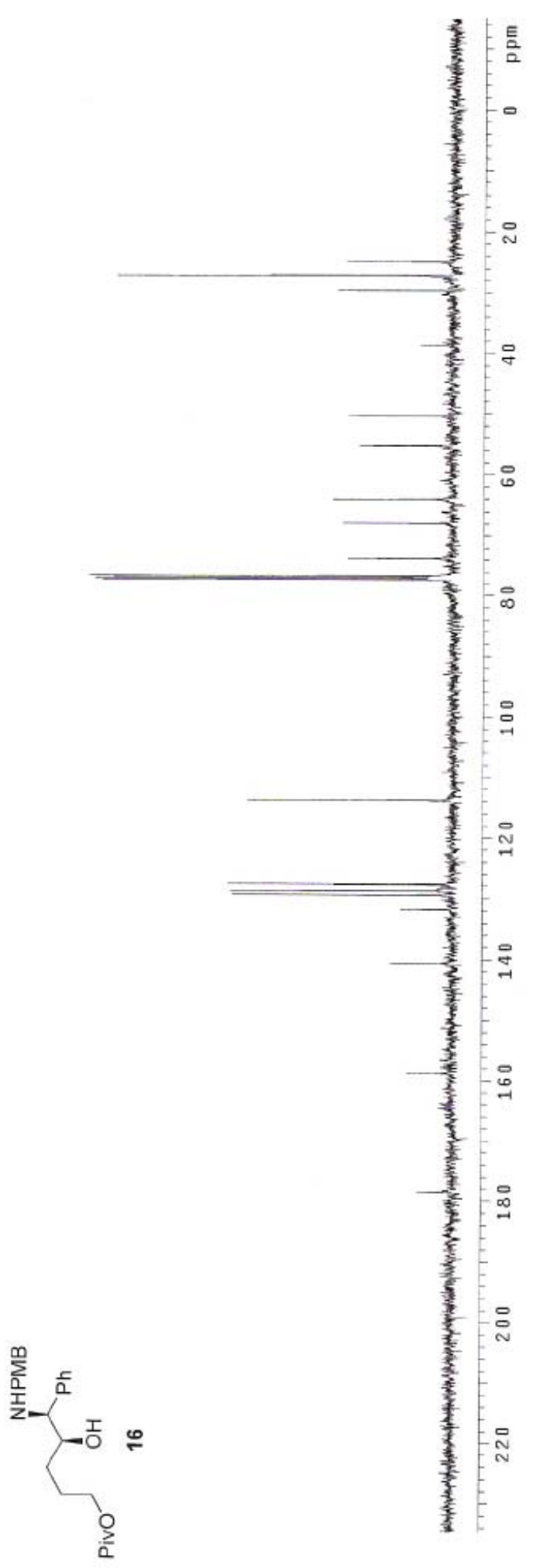




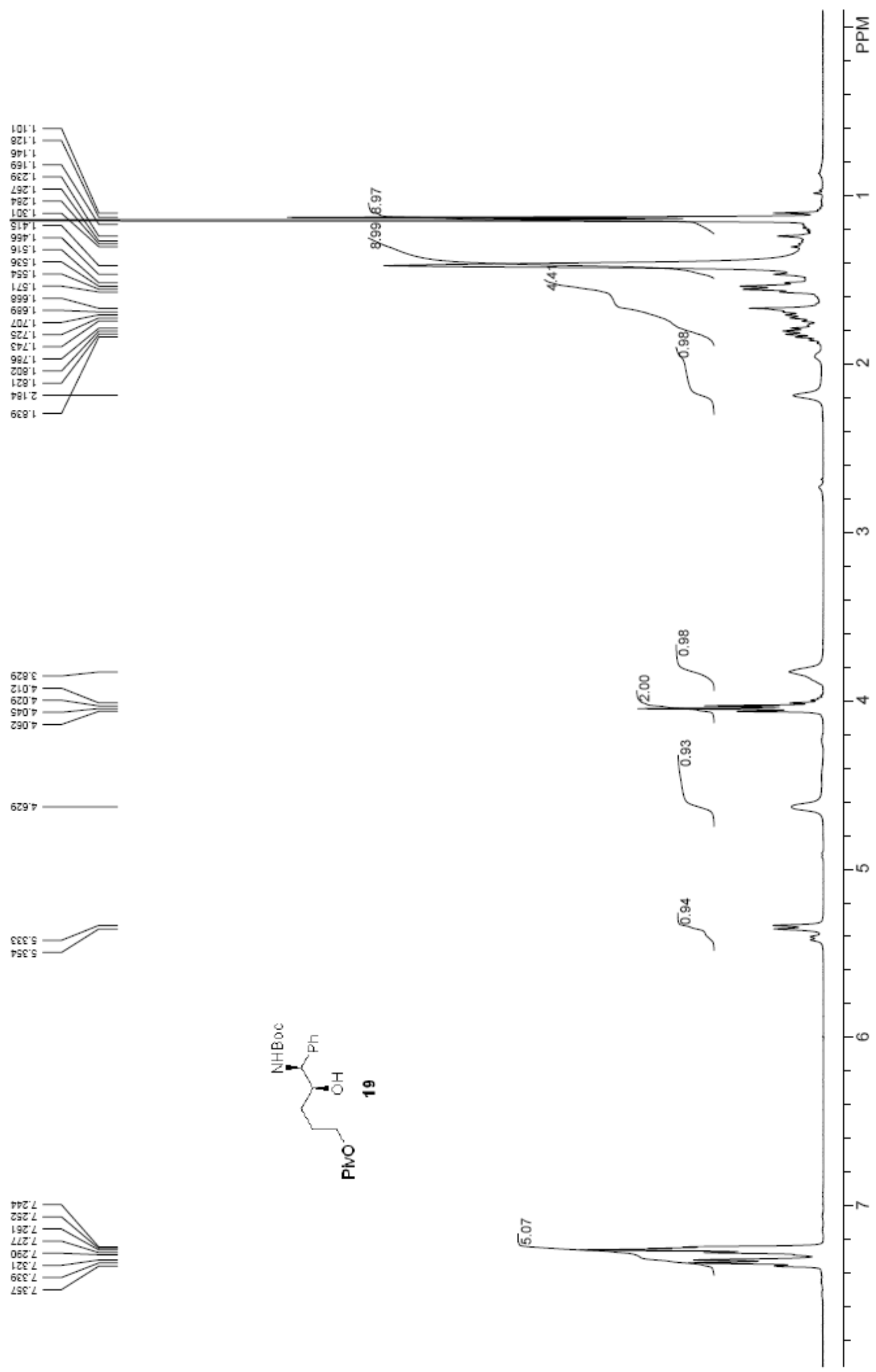




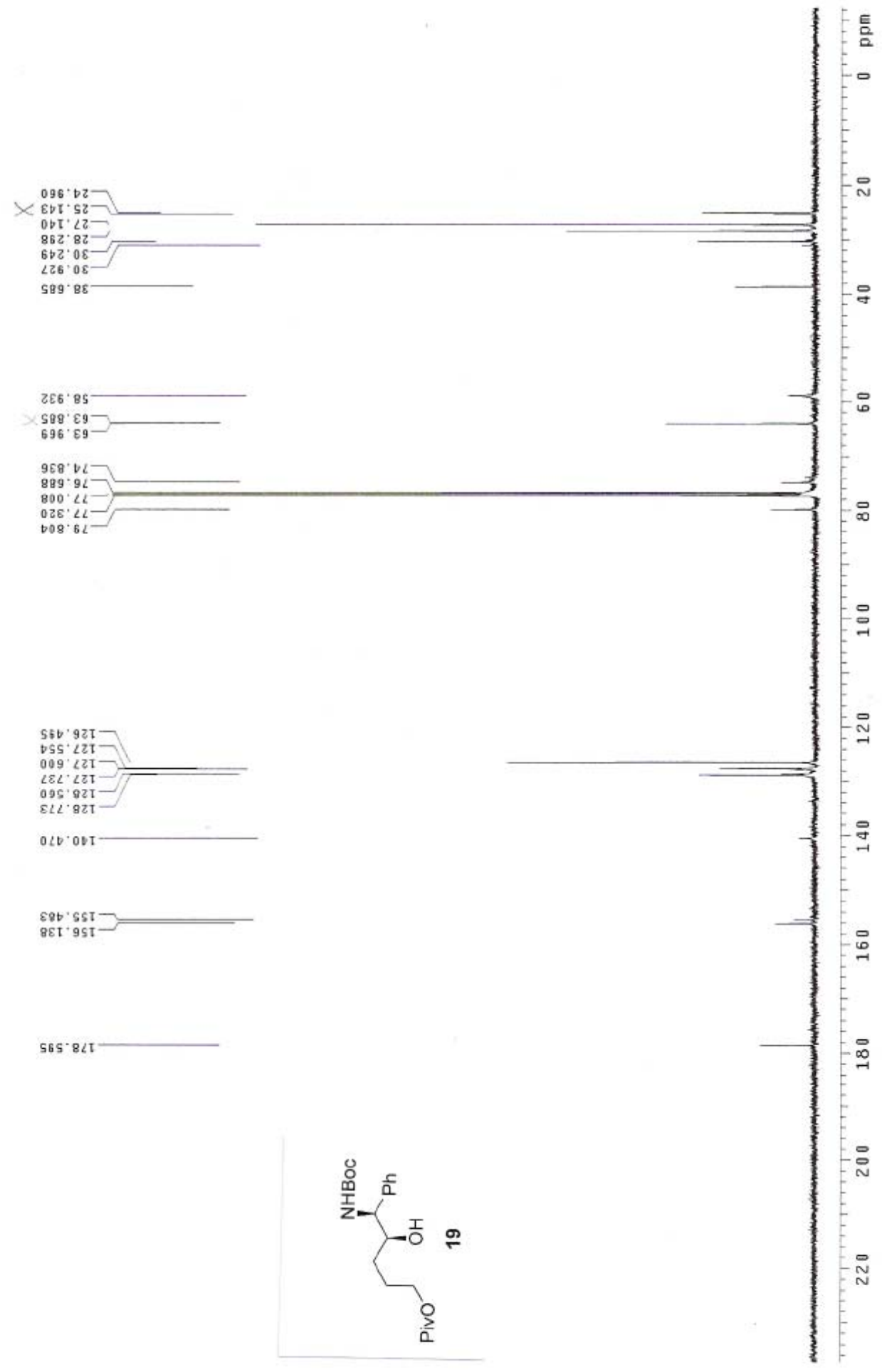




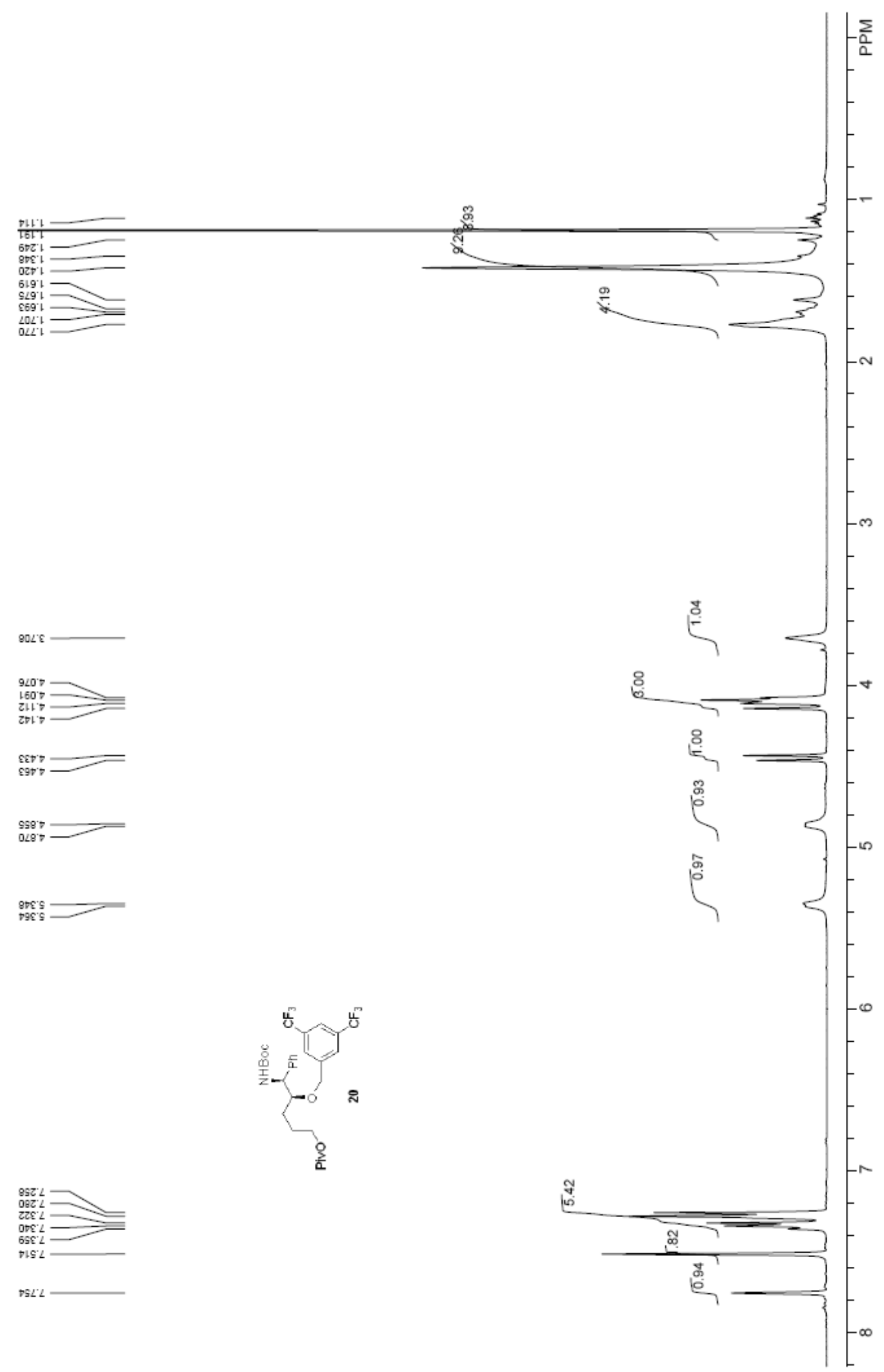




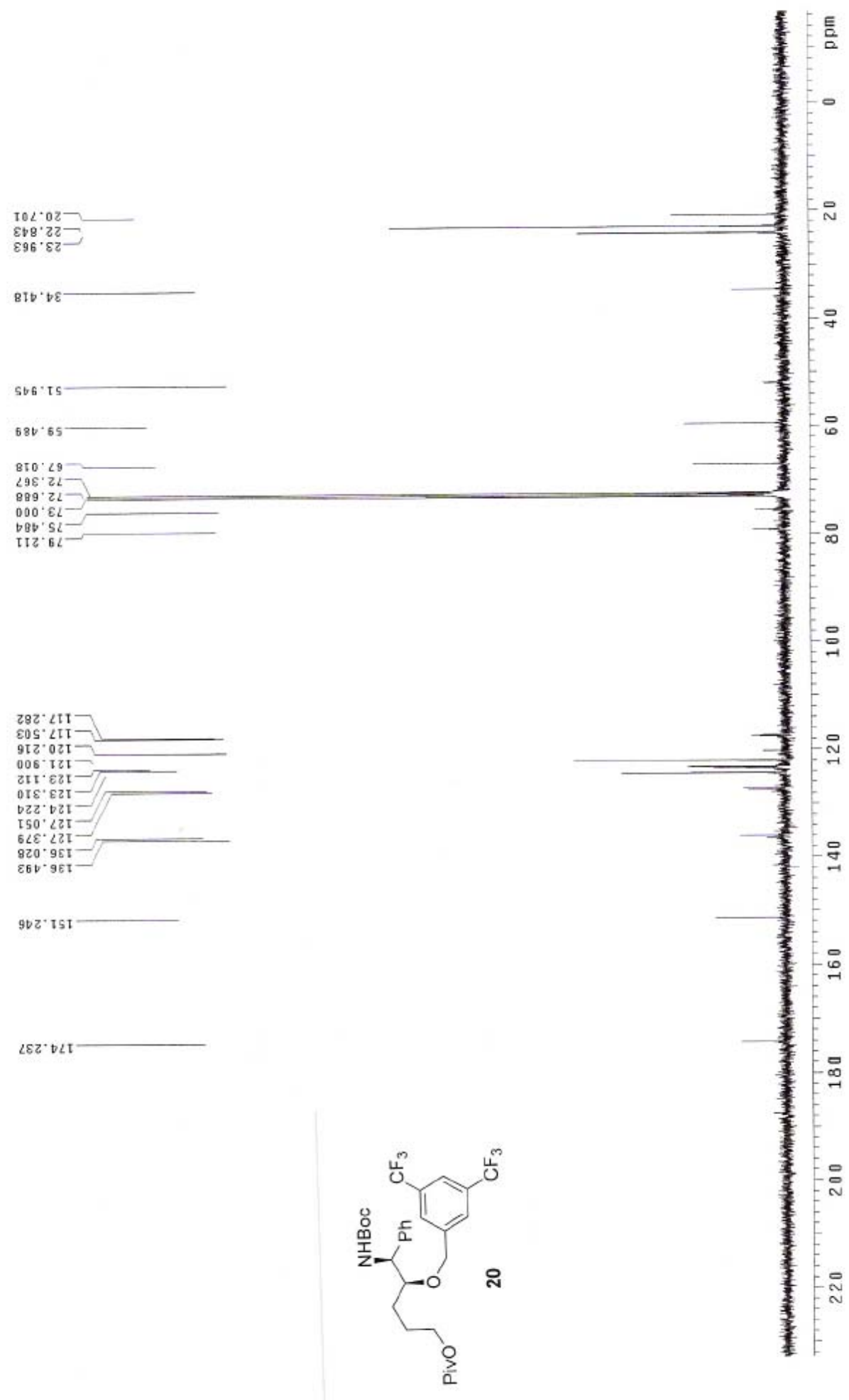




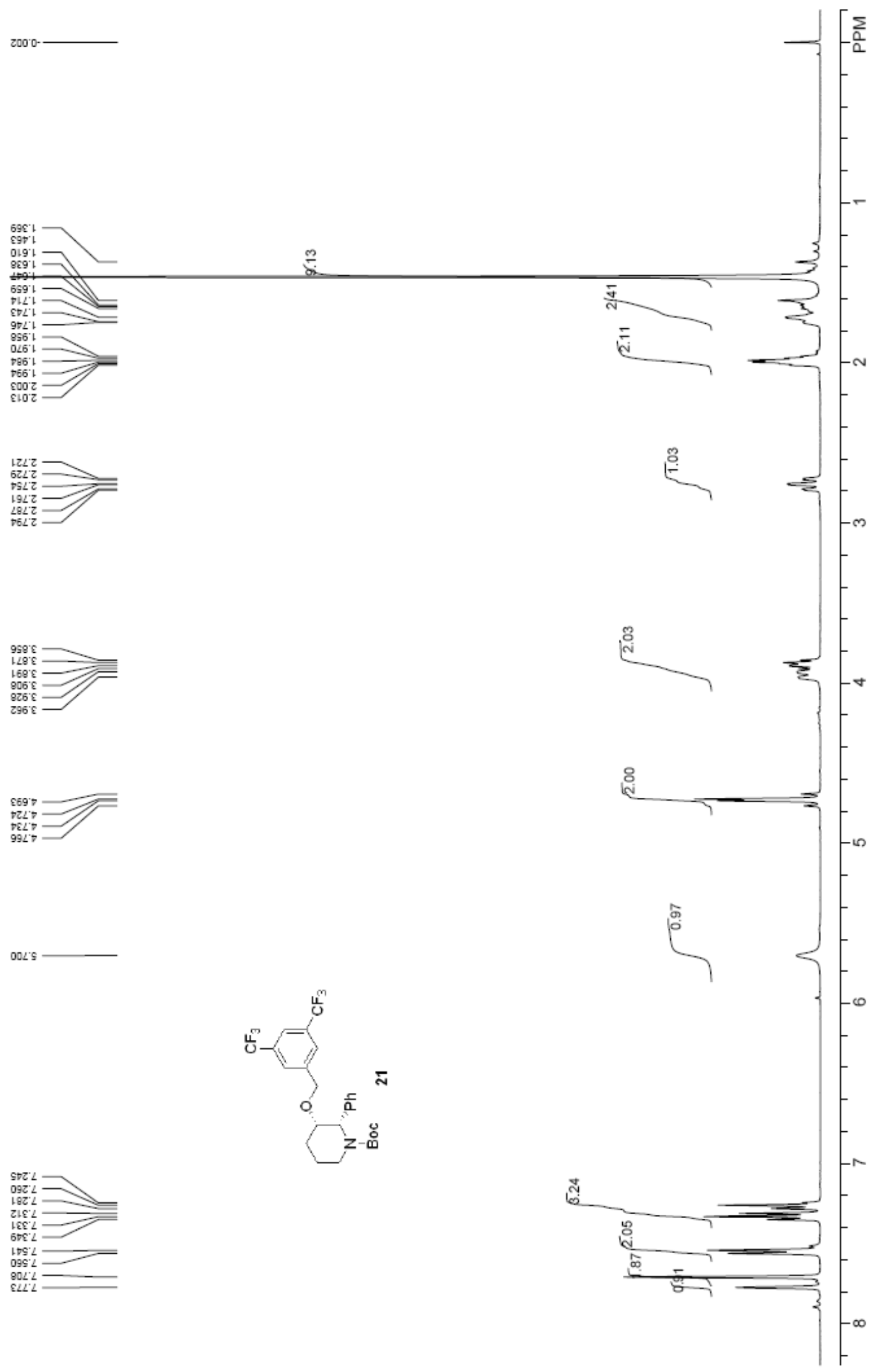




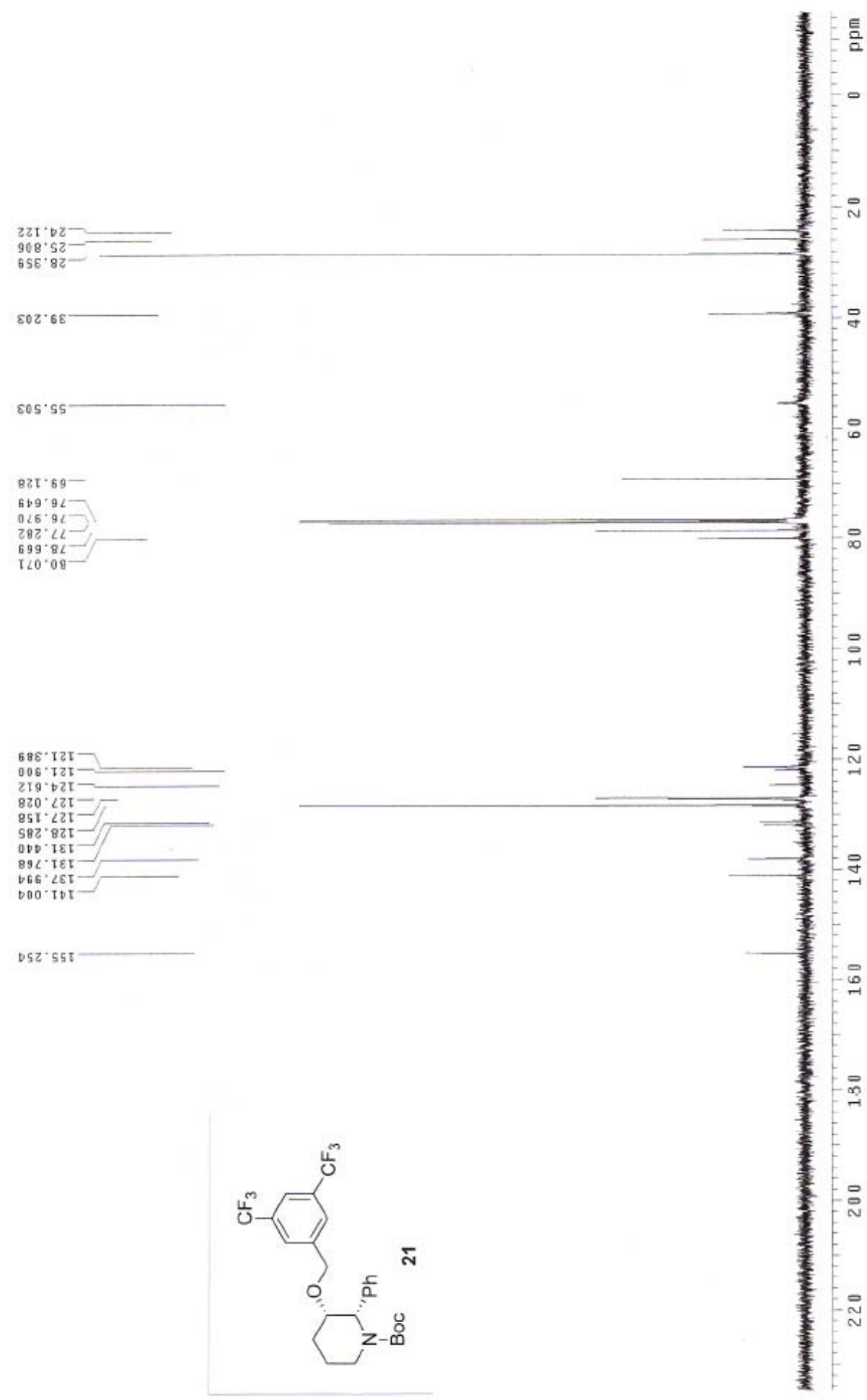



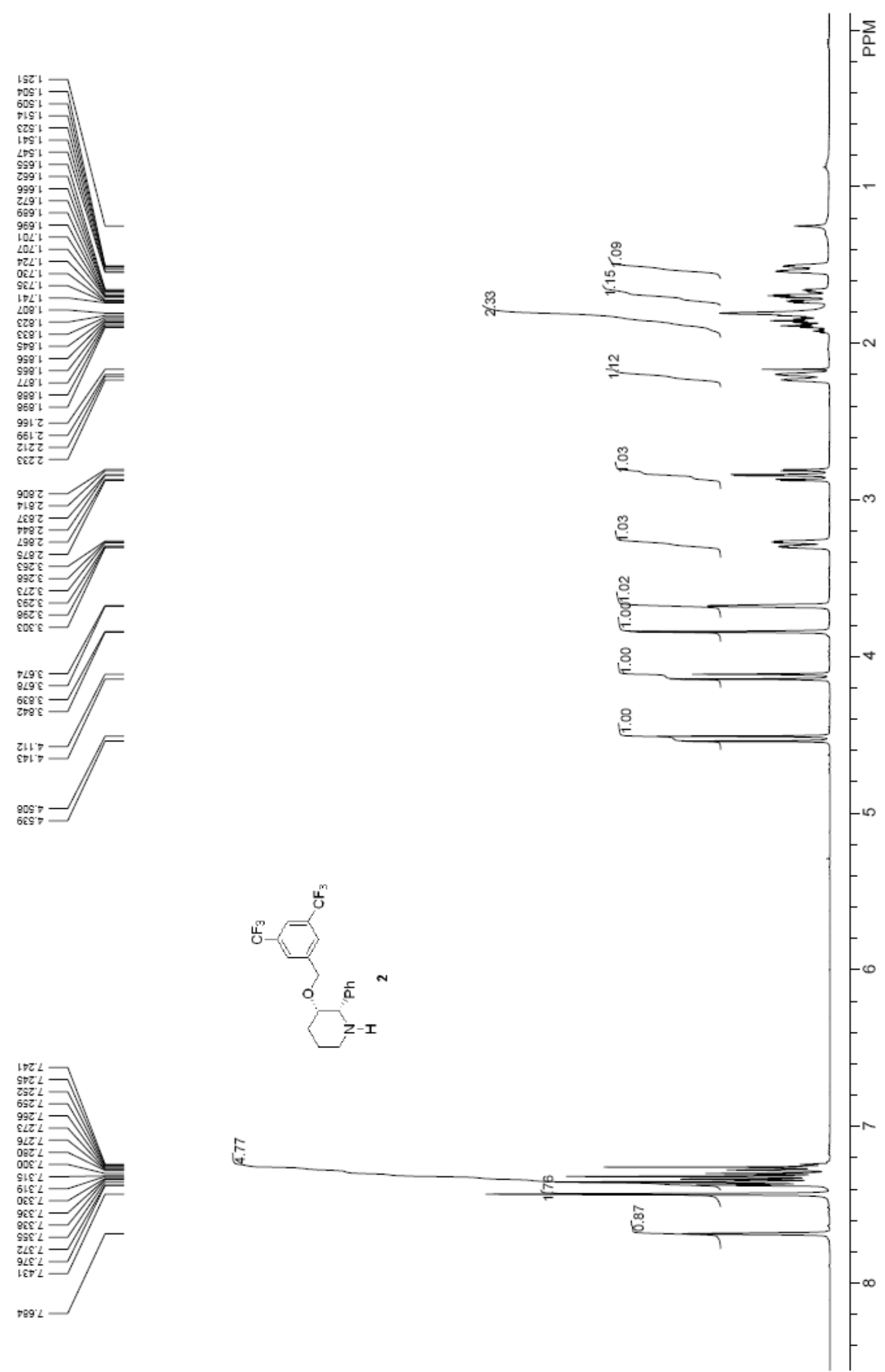


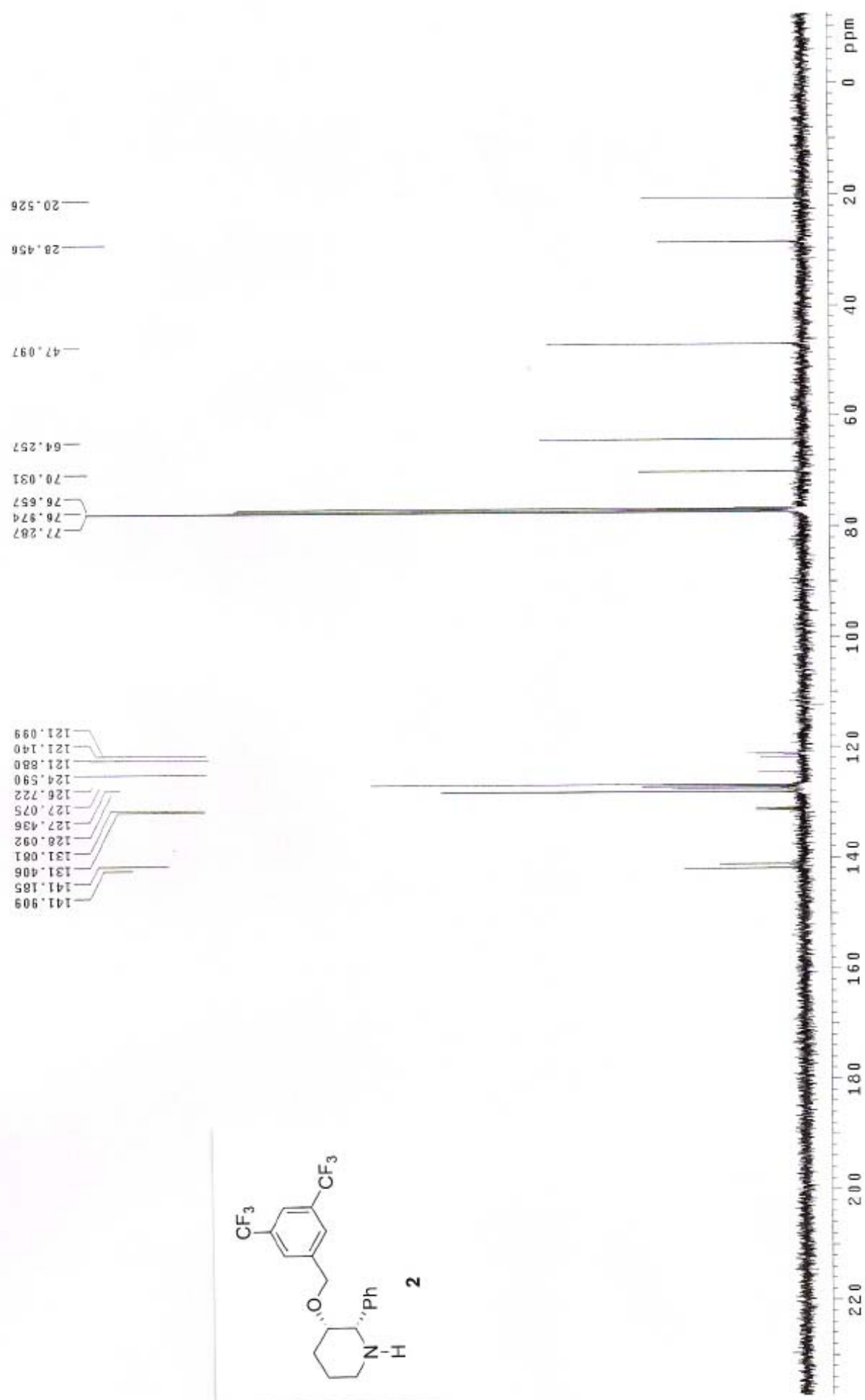

